\title{
Oceanic Rain Rate Retrievals Using TRMM Microwave Imager Multi-channel Brightness Temperatures during the 1998 SCSMEX
}

\author{
Wann-Jin Chen ${ }^{1, *}$ and Ching-Chung $\mathrm{Li}^{1}$ \\ (Manuscript received 23 August 1999, in final form 1 May 2000)
}

\begin{abstract}
The purpose of this paper is to retrieve the oceanic rain rate $(R R)$ over waters near Taiwan and Luzon from the Tropical Rainfall Measuring Mission (TRMM) Microwave Imager (TMI) multi-channel brightness temperatures (Tbs). In addition to improving heavy rainfall forecasting by providing quantitative oceanic RR estimates and possible movement direction of Mesoscale Convective Systems (MCSs), another objective of this paper is to overcome the lack of oceanic conventional observations in heavy rainfall forecasting during the Mei-Yu season. Rainfall caused by MCSs during the 1998 South China Sea Monsoon Experiment (SCSMEX) was studied using TMI nine-channel Tbs, the hourly RR from ground rain gauges, and Geostationary Meteorological Satellite (GMS) infrared (IR) Tbs. In this paper, the domain ranges from $110^{\circ} \mathrm{E}$ to $130^{\circ} \mathrm{E}$ and from $15^{\circ} \mathrm{N}$ to $30^{\circ} \mathrm{N}$. Two oceanic $R R$ retrievals taken on 3 June 1998 are shown and examined. The results show that a TMI nine-channel Tbs-RR equation can retrieve the amounts of heavy rainfall caused by the MCSs that often occur during the summer monsoon season in southeastern China, the northern part of the South China Sea, Luzon, and southern Taiwan. The RR retrievals were quantitatively consistent with the rainfall observations made on nearby islands. The GMS IR Tb $240 \mathrm{~K}$ isotherms included most of the TMI microwave (MW) Tbs retrieved rainfall region. The heaviest rainfall region was more or less included in the area where the IR Tb was colder than $210 \mathrm{~K}$. The region had a tendency to be concentrated in the forward part of the MCS in the direction of its movement. Moreover, analyses of the rainfall events that occurred in southern Taiwan during the SCSMEX period show that there was local rainfall enhancement caused by the orographic features of the island.
\end{abstract}

\footnotetext{
${ }^{1}$ Department of Applied Physics, Chung Cheng Institute of Technology, National Defense University, Tao-Yuan, Taiwan, ROC

* Corresponding author address: Associate Prof. Wann-Jin Chen, Department of Applied Physics, Chung Cheng Institute of Technology, National Defense University, Ta-Hsi, Tao-Yuan, 33501, Taiwan, ROC; Email: wannjin@ ccit.edu.tw
} 


\section{(Key words: SCSMEX, TRMM, TMI, GMS, MCS, Mei-Yu, Oceanic rain rate, Heavy rainfall forecasting)}

\section{INTRODUCTION}

In summer, the strong convective activity over the northern South China Sea is quite remarkable. In this season, moist southwesterly winds prevail over the South China Sea. Heavy rainfall associated with the Mei-Yu front or with Mesoscale Convective Systems (MCSs) cause severe damage to regional economies, including those of Taiwan, Luzon, and southern China. Flash flooding often occurs during May and June of the Mei-Yu season as thermal conditions and terrain forces interact with the ample supply of tropical moisture and the front (Akaeda et al. 1995). Heavy rainstorms induced by various kinds of convective systems develop around the Mei-Yu front affecting society in major ways (Masahito and Shinoda 1995). Thus, heavy rainfall forecasting is the most important and challenging task to weather forecasters in this area. Since most of the heavy rainfall systems come from the open ocean, the major shortcoming of conventional rainfall forecasting is the lack of significant rainfall observations over the oceans. Therefore oceanic observations from space made by satellites are indispensable.

Using meteorological satellites to survey the atmospheric parameters has been done for decades. On board the TRMM (Tropical Rainfall Measuring Mission) satellite, the TRMM Microwave Imager (TMI), the Visible Infrared Scanner (VIRS), and the Precipitation Radar (PR) are all designed to monitor tropical and subtropical precipitation. This satellite was launched on November 27, 1997, to provide at least 3 years precipitation measurements in the tropics. In this paper, TMI microwave (MW) brightness temperatures (Tbs) will be used to estimate quantitative oceanic rain rates (RRs) during the South China Sea Experiment (SCSMEX). In 1998, from May to June, the SCSMEX, supported by the U.S., Taiwan, China and Australia, proceeded in the vicinity of Dongshatao $\left(20.7^{\circ} \mathrm{N}, 116.7^{\circ} \mathrm{E}\right)$ in the northern part of the South China Sea. Meanwhile, a Heavy Rainfall Experiment was conducted over Taiwan. SCSMEX was designed to study the water and energy cycles in the Asian monsoon regions, in order to improve quantitative precipitation predictions. It was designed to provide a better understanding of the physical processes in the East Asia monsoon, including its onset, maintenance and variability throughout Southeast Asia and southem China. The heavy rainfall observations are necessary to understand the occurrence and mechanism of heavy rainfall, and the influence of monsoons and Mei-Yu fronts on precipitation. Many observations were made during SCSMEX. TMI multi-channel MW Tbs, surface rain gauge measurements from Dongshatao and other islands, surface rain gauge network measurements from Taiwan, and Geostationary Meteorological Satellite 5 (GMS-5) infrared (IR) measurements were all examined and used to analyze the oceanic RR and its influence on southern Taiwan.

The purpose of this paper then is to retrieve oceanic RRs during the Mei-Yu season from the TMI nine-channel Tbs, in addition to improving conventional heavy rainfall predictions by providing information as to quantitative oceanic RR estimates and possible direction of MCS movement. Satellite visible/ IR data gives information of only cloud top properties, while MW 
data has historically been limited due to its poor spatial resolutions (Hong et al. 1999). Since MWs are little affected by clouds and can thus penetrate them, they are better than IR and visible light for the purposes of sensing precipitation over the oceans. MW radiation interacts strongly with raindrops in the entire atmosphere, so that rainfall sensed by MW radiometers can be considered to provide more direct and accurate instantaneous estimates. However, the TRMM is a polar-orbiting satellite and thus doesn't allow for continuous rainfall monitoring. Fortunately, the visible and IR sensors on board the geo-synchronous observatory are, on the other hand, available on a global scale, at about 1-hour intervals. Therefore, between two successive MW observations, the GMS IR sensors were used to monitor the MCSs so that the lack of conventional oceanic observations, which are required for heavy rainfall forecasting, could be overcome by observations from the various satellites. Thus, a good way to develop a heavy rainfall forecasting scheme is to combine satellite MW and IR data. The MW measurements from space are introduced in section 2, including MW radiometer data, the MW properties, and TMI data descriptions. Rain gauge measurements from nearby islands are introduced in section 3. Section 4 presents the oceanic rain rate retrieval algorithm, the results, and an analysis. In section 5, a local rainfall enhancement case is described and then summarized. Section 6 gives the conclusions.

\section{MICROWAVE MEASUREMENTS FROM SPACE}

\subsection{Microwave Radiometers in Space}

The launch of Seasat-A and Nimbus-G in 1978, both carrying Scanning Multi-channel Microwave Radiometers (SMMR) has opened a new era in MW radiometric observations of the oceanic surface (Wilheit and Chang 1980a,b). The Defense Meteorological Satellite Program (DMSP) was launched on 19 June 1987 with the first Special Sensor Microwave Imager (SSM/I) aboard. The SSM/I is a four-frequency $(19.4,22.235,37$, and $85.5 \mathrm{GHz})$, dual polarized (except for $22.235 \mathrm{GHz}$ which is vertically polarized only) MW radiometer, and the DMSP orbits at an altitude at $833 \mathrm{~km}$ (Holinger et al. 1987). The TMI on the TRMM satellite is a passive MW precipitation instrument that has been improved relative to the SSM/I on the DMSP. The TRMM's lower-altitude orbit $(350 \mathrm{~km})$ and its inclination of 35 degrees to the Equator results in better spatial resolution and fewer beam-filling problems than the DMSP has (Simpson et al. 1996).

\subsection{TMI Data}

The TMI has been improved relative to SSM/I by two important changes. The first is the addition of a $10.7 \mathrm{GHz}$ channel, having a much more nearly linear relationship between Tbs and RR; the other one is the slight change of the water vapor channel frequency to $21.3 \mathrm{GHz}$, to reduce saturation in the moist tropics (Simpson et al. 1996).

Table 1 shows the TMI characteristics (see Kummerow et al. 1998). The TMI scans the earth with a conical mode. The antenna beam observes the earth 49 degrees away from nadir, and is thus at an incident angle of about $52.8^{\circ}$ at the earth's surface. It rotates about the nadir 
Table 1. The characteristics of TMI.

\begin{tabular}{|c|c|c|c|c|c|c|c|c|c|}
\hline$\overline{C H A N N E L}$ & 1 & 2 & 3 & 4 & 5 & 6 & 7 & 8 & 9 \\
\hline Frequency $(\mathrm{GHz})$ & 10.7 & 10.7 & 19.4 & 19.4 & 21.3 & 37 & 37 & 85.5 & 85.5 \\
\hline Polarization & V & $\mathrm{H}$ & V & $\mathrm{H}$ & V & V & $\mathrm{H}$ & V & $\mathrm{H}$ \\
\hline Beam width (GHz) & 0.1 & 0.1 & 0.5 & 0.5 & 0.2 & 2 & 2 & 3 & 3 \\
\hline Beam width(deg) & 3.68 & 3.75 & 1.90 & 1.88 & 1.70 & 1.00 & 1.00 & 0.42 & 0.43 \\
\hline EFOV-DT $(\mathrm{km})$ & 63.2 & 63.2 & 30.4 & 30.4 & 22.6 & 16.0 & 16.0 & 7.2 & 7.2 \\
\hline EFOV-CT $(\mathrm{km})$ & 9.1 & 9.1 & 9.1 & 9.1 & 9.1 & 9.1 & 9.1 & 4.6 & 4.6 \\
\hline $\begin{array}{l}\text { Integration time } \\
{[\mathrm{ms} / \mathrm{sample}]}\end{array}$ & 6.60 & 6.60 & 6.60 & 6.60 & 6.60 & 6.60 & 6.60 & 3.30 & 3.30 \\
\hline $\begin{array}{l}\text { No of EFOVs } \\
\text { per scan }\end{array}$ & 104 & 104 & 104 & 104 & 104 & 104 & 104 & 208 & 208 \\
\hline $\begin{array}{l}\text { No of Samples } \\
\text { per beam width }\end{array}$ & 4 & 4 & 2 & 2 & 2 & 1 & 1 & 1 & 1 \\
\hline $\begin{array}{l}\text { No of BEFOVs } \\
\text { per scan }\end{array}$ & 26 & 26 & 52 & 52 & 52 & 104 & 104 & 208 & 208 \\
\hline footprint $(\mathrm{km} \times \mathbf{k m})$ & $63 \times 37$ & $63 \times 37$ & $30 \times 18$ & $30 \times 18$ & $23 \times 18$ & $16 \times 9$ & $16 \times 9$ & $7 \times 5$ & $7 \times 5$ \\
\hline \multicolumn{10}{|c|}{ Scan Mode : forward conical mode ( conical angle $=49^{\circ}$; incident angle $\theta=52.8^{\circ}$ ) } \\
\hline \multicolumn{10}{|c|}{ TMI Antenna : $31.6 \mathrm{rpm} ;(1.9 \mathrm{sec} / \mathrm{scan})$} \\
\hline \multicolumn{4}{|l|}{ Reading data sector : } & \multicolumn{6}{|c|}{130 degree } \\
\hline \multicolumn{4}{|l|}{ Swath : } & \multicolumn{6}{|c|}{ about $760 \mathrm{~km}$} \\
\hline \multicolumn{4}{|l|}{ TRMM speed : } & \multicolumn{6}{|c|}{$7.3 \mathrm{~km} / \mathrm{sec}$} \\
\hline \multicolumn{3}{|c|}{ TRMM speed (surface) : } & & \multicolumn{6}{|c|}{$6.9 \mathrm{~km} / \mathrm{sec}$ (forward $14 \mathrm{~km} / \mathrm{scan}$ ) } \\
\hline
\end{tabular}

axis with a constant speed of $31.6 \mathrm{rpm}$, looking forward. Dual polarization measurements are taken at $10.7,19.4,37$, and $85.5 \mathrm{GHz}$, whereas only the vertical polarization measurement is observed at $21.3 \mathrm{GHz}$. The spatial resolutions of these channels vary from $9.1 \mathrm{~km} \times 63.2 \mathrm{~km}$ at $10.7 \mathrm{GHz}$ to $4.6 \mathrm{~km} \times 7.2 \mathrm{~km}$ at $85.5 \mathrm{GHz}$. The TMI level-1B11 data are the instrument data in full resolution with calibration and Earth location computed (for a detailed definition of the data levels, see Simpson et al. 1996), and they were used in this paper to retrieve the oceanic RRs.

Passive MW remote sensing assumes that the field of view (FOV) is uniformly filled with precipitation. The $\mathrm{Tb}$ increases with the $\mathrm{RR}$ due to the effect of emission of rain. The $\mathrm{Tb}$ decreases at higher RRs, as the effect of scattering by hydrometeors takes on a more dominant role (Chiu et al. 1990). By using a five-layer radiative transfer physical forward model, introduced by Kummerow et al. (1989), the relationship between the TMI MW channels and the RRs are studied. The model outputs Tbs after radiative transfer computations. The modeling results show that the linear ranges for $\mathrm{Tb}_{10.7 \mathrm{GHz}(\mathrm{V})}$ and $\mathrm{Tb}_{10.7 \mathrm{GHz} \mathrm{H})}$ are longer than those of the other channels. At $85.5 \mathrm{GHz}$, the effect of scattering induced by ice and large size rain strongly dominates the radiative transfer process. For RRs larger than about $2 \mathrm{~mm} / \mathrm{hr}$, the $\mathrm{Tb}_{85.5 \mathrm{CHz}(\mathrm{V})}$ and $\mathrm{Tb}_{85.5 \mathrm{GHz}(\mathrm{H})}$ are monotonically decreasing functions of $\mathrm{RR}$. The $\mathrm{Tb}_{37 \mathrm{GHz}(\mathrm{V})}$ and $\mathrm{Tb}_{37 \mathrm{GHz}(\mathrm{H})}$ quickly reach the saturation point, and then behave as monotonically decreasing functions of 
the RR. However, the decreasing slope is less than that of $85.5 \mathrm{GHz}$. Obviously, the Tbs are not monotonic functions of the RR for channels with frequencies lower than $37 \mathrm{GHz}$. The RR is a nonlinear function of the Tbs. However, due to mixing information received by the antenna and the beam filling bias in remote sensing (Chiu et al. 1990), modeled results are rarely found. On the contrary, Spencer (1986) indicated that, for RRs lower than $40 \mathrm{~mm} / \mathrm{hr}$, the relationship between the SMMR $37 \mathrm{GHz}$ Tbs and the radar derived $\mathrm{RR}$ is almost linear.

\section{ISLAND RAIN GAUGE MEASUREMENTS}

Seven islands were chosen within the study domain to monitor their rainfall characteristics. From north to south, they are Pengchiayu $\left(25.6^{\circ} \mathrm{N}, 122.1^{\circ} \mathrm{E}\right)$, Penghu $\left(23.6^{\circ} \mathrm{N}, 119.6^{\circ} \mathrm{E}\right)$, Tungchitao $\left(23.3^{\circ} \mathrm{N}, 120.7^{\circ} \mathrm{E}\right)$, Lutao $\left(22.7^{\circ} \mathrm{N}, 121.5^{\circ} \mathrm{E}\right)$, Liuchiu $\left(22.3^{\circ} \mathrm{N}, 120.4^{\circ} \mathrm{E}\right)$, Lanyu $\left(22.0^{\circ} \mathrm{N}, 121.6^{\circ} \mathrm{E}\right)$ and Dongshatao $\left(20.7^{\circ} \mathrm{N}, 116.7^{\circ} \mathrm{E}\right)$. Their rainfall measurements are assumed to be the same as for locations over the waters around them.

The rainfall measurements on Pengchiayu, Penghu, Tungchitao and Lanyu are from manwatched rain gauge data. The rain observations on Liuchiu and Lutao were made by automatic rain gauges. All sensors are part of the rain measurement system of the Central Weather Bureau on Taiwan. Rainfall observations at Dongshatao were carried out by the Integrated Sounding System operated by a crew from Taiwan's National Central University during the SCSMEX.

From a total of seven stations, 9408 individual rain measurements ( 7 stations $\times 24$ hours $\times 56$ days) were made from 1 May to 25 June 1998 . There were only 1044 raining hours altogether, meaning a probability of rainfall occurrence of about $11.1 \%$ during SCSMEX over waters in this region. Table 2 shows the rainfall occurrence statistics and all the rainfall times are divided into 4 intervals: 1-15 May, 16-31 May, 1-15 June, and 16-25 June. The percentage of the total rain amounts are $29.83 \%$ and $51.50 \%$ for the second and third time intervals, respectively. Therefore, the amount of rain that accumulated from 16 May to 15 June is $81.33 \%$ of the total amount. From 16 June to 25 June, the accumulated rain amounts are 3.9, 0.8, 3.8, and $2 \mathrm{~mm}$ for Pengchiayu, Penghu, Tungchitao, and Dongshatao, respectively. However, during the same time interval, the accumulated rain measurements are 202.5 and 59. $5 \mathrm{~mm}$ for Lutao and Liuchiu, respectively. Almost no rain was observed on the islands after 16 June, except for Lutao, Liuchiu, and Lanyu. However, the accumulated rain amount was found to be $158 \mathrm{~mm}$ from 21Z 16 May to $01 \mathrm{Z} 17$ May on Tungchitao, which means the rain accumulation on Tungchitao from 20:00 UTC 16 May to 01:00 UTC 17 May was $158 \mathrm{~mm}$. Moreover, the accumulated rain amount was $175 \mathrm{~mm}$ within 5 hours on Liuchiu from $14 \mathrm{Z}$ to $18 \mathrm{Z}$ on 29 May.

In this paper we divide the rain rates into three intensity levels: Level 1 is for $R R<5 \mathrm{~mm} /$ $\mathrm{hr}$, Level 2 for $5 \mathrm{~mm} / \mathrm{hr} \leq \mathrm{RR} \leq 10 \mathrm{~mm} / \mathrm{hr}$ and Level 3 for $\mathrm{RR}>10 \mathrm{~mm} / \mathrm{hr}$. For all observations, the proportion of Levels 1,2 and 3 is $79.3 \%, 11.7 \%$ and $9 \%$, respectively. The statistics show that the conditional probability of occurrence for RRs $>10 \mathrm{~mm} / \mathrm{hr}$ is $9 \%$ in this region during the SCSMEX period. On the other hand, for RR $\leq 10 \mathrm{~mm} / \mathrm{hr}$ events, the conditional probability is $91 \%$, including $11.7 \%$ for $5 \mathrm{~mm} / \mathrm{hr} \leq \mathrm{RR} \leq 10 \mathrm{~mm} / \mathrm{hr}$ and $79.3 \%$ for $\mathrm{RR}<5 \mathrm{~mm} / \mathrm{hr}$. The unconditional occurrence probability for $\mathrm{RR}>10 \mathrm{~mm} / \mathrm{hr}$ is about only $1 \%(9 \% \times 11.1 \%)$. Thus the 
Table 2. The statistics for rainfall events observed during the SCSMEX.

\begin{tabular}{|c|c|c|c|c|c|}
\hline \multirow{3}{*}{\multicolumn{2}{|c|}{$\begin{array}{c}\text { Rain Stations } \\
\text { \& Time Interval }\end{array}$}} & \multirow{2}{*}{\multicolumn{3}{|c|}{$\begin{array}{l}\text { Rain Rate }(\mathrm{mm} / \mathrm{hr}) \text { Range } \\
\text { \& Rainfall Times }\end{array}$}} & \multirow[t]{2}{*}{ 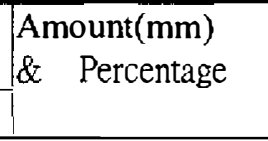 } \\
\hline & & & & & \\
\hline & & & & & \\
\hline \multirow[t]{4}{*}{ Pengchiayu } & 1-15 May & 21 & 1 & 1 & $29.3 / 0.8 \%$ \\
\hline & 16-31 May & 55 & 2 & 0 & $58.4 / 1.63 \%$ \\
\hline & 1-15 June & 64 & 6 & 4 & $153.2 / 4.3 \%$ \\
\hline & 16-25 June & 8 & 0 & 0 & $3.9 / 0.1 \%$ \\
\hline \multirow[t]{4}{*}{ Penghu } & 1-15 May & 7 & 0 & 0 & $12 / 0.3 \%$ \\
\hline & 16-31 May & 23 & 1 & 3 & $92.1 / 2.6 \%$ \\
\hline & 1-15 June & 47 & 6 & 3 & $152.8 / 4.3 \%$ \\
\hline & 16-25 June & 2 & 0 & 0 & $0.8 / 0.02 \%$ \\
\hline \multirow[t]{4}{*}{ Tungchitao } & 1-15 May & 15 & 1 & 0 & $37 / 1 \%$ \\
\hline & 16-31 May & 18 & 5 & 6 & $261.5 / 7.3 \%$ \\
\hline & 1-15 June & 48 & 9 & 7 & $245 / 6.8 \%$ \\
\hline & 16-25 June & 5 & 0 & 0 & $3.8 / 0.1 \%$ \\
\hline \multirow[t]{4}{*}{ Lutao } & 1-15 May & 17 & 4 & 1 & $61.3 / 1.7 \%$ \\
\hline & 16-31 May & 45 & 0 & 5 & $36.5 / 1 \%$ \\
\hline & 1-15 June & 63 & 3 & 0 & $78.5 / 2.2 \%$ \\
\hline & 16-25 June & 30 & 6 & 6 & $202.5 / 5.7 \%$ \\
\hline \multirow[t]{4}{*}{ Liuchiu } & 1-15 May & 6 & 0 & 0 & $3 / 0.08 \%$ \\
\hline & 16-31 May & 15 & 4 & 0 & $43.5 / 1.2 \%$ \\
\hline & 1-15 June & 77 & 20 & 20 & $593.5 / 16.6 \%$ \\
\hline & 16-25 June & 21 & 4 & 0 & $59.5 / 1.7 \%$ \\
\hline \multirow[t]{4}{*}{$\overline{\text { Lanyu }}$} & 1-15 May & 38 & 4 & 2 & $103.1 / 2.9 \%$ \\
\hline & 16-31 May & 76 & 13 & 10 & $473 / 13.2 \%$ \\
\hline & 1-15 June & 93 & 17 & 8 & $352.4 / 9.8 \%$ \\
\hline & 16-25 June & 8 & 0 & 0 & $12.1 / 0.3 \%$ \\
\hline \multirow[t]{4}{*}{ Dongshatao } & 1-15 May & 12 & 4 & 4 & $141.9 / 4 \%$ \\
\hline & 16-31 May & 24 & 4 & 4 & $104.3 / 2.9 \%$ \\
\hline & 1-15 June & 32 & 8 & 10 & $268.4 / 7.5 \%$ \\
\hline & 16-25 June & 2 & 0 & 0 & $2 / 0.06 \%$ \\
\hline \multirow{2}{*}{\multicolumn{2}{|c|}{$\begin{array}{c}\text { Subtotal \& } \\
\text { Conditional probability* }\end{array}$}} & 828 & 122 & 94 & Total Rainfall \\
\hline & & $79.3 \%$ & $11.7 \%$ & $9 \%$ & $=3585.3 \mathrm{~mm}$ \\
\hline \multicolumn{6}{|c|}{$*$ conditional probability $=$ rainfall times $/$ total rainfall times } \\
\hline \multicolumn{6}{|c|}{$\begin{array}{l}\text { Percentage of total rainfall: } \\
1-15 \text { May }=10.78 \%\end{array}$} \\
\hline \multicolumn{6}{|c|}{$16-31$ May $=29.83 \%$} \\
\hline \multicolumn{6}{|c|}{$1-15$ June $=51.50 \%$} \\
\hline 16-25 June & $7.98 \%$ & & & & \\
\hline
\end{tabular}


RR was rarely over $10 \mathrm{~mm} / \mathrm{hr}$ in this region during SCSMEX. However, some islands had more frequent heavy rainfall events. For example, on Tungchitao, from 16 to $31 \mathrm{June}$, six Level 3 rain events were observed in a total of 29 rainy hours, proportionally $20.7 \%$ of the total rain amount. On Dongshatao, the probability of occurrence of rain events indicates a higher frequency relative to the other islands during the SCSMEX.

\section{OCEANIC RAIN RATE RETRIEVALS}

\subsection{Algorithm}

The RR retrieval flowchart over the ocean is shown in Fig. 1. A statistical method (linear regression) is used to establish the relationship between the TMI multi-channel Tbs and the islands' RR observations. Firstly, the coincidentally observed (Tbs, RR) pairs were collected and the no-rainfall events were filtered out by selecting MW raining thresholds. By using multi- and single-variable linear regression methods, the relationships between island RRs and MW Tbs are established. Then, independent (Tbs, RR) pairs are used to verify these TbsRR equations quantitatively. Finally, the GMS IR images are superimposed, and oceanic RRs retrieved by multi- and single-variable linear regression are examined to verify whether heavy

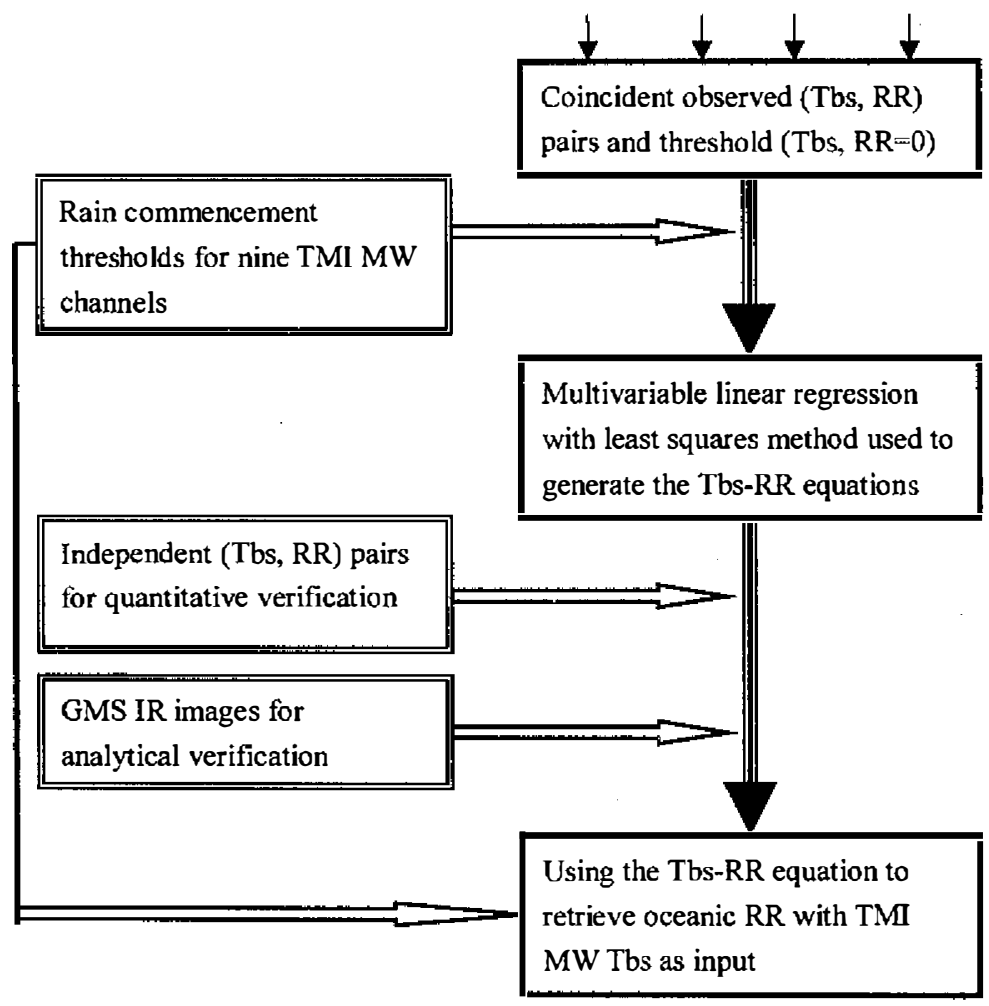

Fig. 1. Flowchart of oceanic RR retrievals. 
rainfall occurs within the deep convective region. Because the TRMM satellite moves across the sky in a very short period of time and the island RR is defined as the amount of rainfall accumulated within one hour, unavoidable errors exist in the RR-Tb linear regression equations.

The data sets used in this paper came from TMI multi-channel Tbs and RR observations from the seven chosen isolated islands. The definition of a coincident (Tbs, RR) pair is that their distance is within $4 \mathrm{~km}$ and their time difference is within 1 hour. Tb1 to Tb9 stand for the Tbs of $10.7 \mathrm{GHz}(\mathrm{V}), 10.7 \mathrm{GHz}(\mathrm{H}), 19.4 \mathrm{GHz}(\mathrm{V}), 19.4 \mathrm{GHz}(\mathrm{H}), 21.3 \mathrm{GHz}(\mathrm{V}), 37 \mathrm{GHz}(\mathrm{V}), 37 \mathrm{GHz}$ $(\mathrm{H}), 85.5 \mathrm{GHz}(\mathrm{V})$ and $85.5 \mathrm{GHz}(\mathrm{H})$, respectively. Using the TMI Tbs statistics for no-rainfall events, the rain thresholds for the nine TMI channels are determined. The rain thresholds and their deviations from $\mathrm{Tb} 1$ to $\mathrm{Tb} 9$ are $179.87 \pm 2.64 \mathrm{~K}, 103.29 \pm 4.42 \mathrm{~K}, 217.08 \pm 3.95 \mathrm{~K}, 164$. $75 \pm 7.04 \mathrm{~K}, 246.25 \pm 4.16 \mathrm{~K}, 229.64 \pm 4.80 \mathrm{~K}, 180.19 \pm 9.13 \mathrm{~K}, 276.83 \pm 2.87 \mathrm{~K}$ and $259.78 \pm 5$. $75 \mathrm{~K}$, respectively. These are used to filter out the coincident $(\mathrm{Tb}, \mathrm{RR})$ pairs for which they are no-rainfall events but that agree with the definition of coincidence. After these checking processes, 37 coincident (Tbs, RR) pairs are left and used to establish Tbs-RR linear regression equations, which are dedicated to retrieve oceanic RR in this area, using TMI multichannel Tbs as inputs.

Of the 37 coincident (Tbs, RR) pairs, $35 \mathrm{RR}$ pairs had intensities less than $10 \mathrm{~mm} / \mathrm{hr}$, while the other two pairs had 17 and $18 \mathrm{~mm} / \mathrm{hr}$, respectively. Since there are only 2 coincident pairs whose RRs are greater than $10 \mathrm{~mm} / \mathrm{hr}$ and the unconditional occurrence probability for $\mathrm{RR}>10 \mathrm{~mm} / \mathrm{hr}$ is about $1 \%$ during the SCSMEX period, the relationship of Tbs to RR is treated as linear in this paper. Because no other rain measurements in this region could be used to verify the TMI oceanic RR retrievals, three coincident (Tbs, $R R$ ) pairs are used as independent pairs to verify the RR retrievals, quantitatively. Thus, only 32 (Tbs, RR) pairs are used to establish Tbs-RR equations. In this paper, linear regression, including the least squares method, is used to obtain the linear regression Tbs-RR equation.

Table 3 shows the TMI single and multi-channel linear regression Tb-RR or Tbs-RR equations. It is found the values of the determination coefficient $\left(R^{2}\right)$ of the multi-channel Tbs$R R$ equations are all larger than the values of the single-channel Tb-RR equations. Among these equations, the maximum $R^{2}$ value is 0.7993 for the nine-channel Tbs- $R R$ equation. Three independent (Tbs, RR) pairs are used to check the Tbs-RR equation. The results are shown in Table 4 . The RRs retrieved by the nine-channel Tbs-RR equations are quite consistent with the observations. Therefore, this nine-channel linear regression Tbs-RR equation is used to retrieve oceanic RRs in this paper. Moreover, GMS-5 satellite IR images are used to investigate whether the retrieved heavy rainfall regions were accompanied with a cold cloud top surface or not, in accordance with the idea that areas of higher convective cloud in satellite images are often associated with more precipitation (Arkin 1979).

\subsection{Results and Aanlyses}

The TMI MW Tbs from the TRMM orbital numbers \#2961 and \#2966 are used as inputs into the Tbs-RR equation to retrieve oceanic RR. The times of \#2961 and \#2966 are 15:25Z and 23:29Z on 3 June 1998, respectively. Figure 2a shows the TMI Tb1 distribution for \#2961, ranging from $100 \mathrm{~K}$ to $260 \mathrm{~K}$. The warm $\mathrm{Tb}$ region over the ocean indicates the rainfall region while the cold $\mathrm{Tb}$ indicates the clear region. Figure $2 \mathrm{~b}$ shows the retrieval of $\mathrm{RR}$ distribution 
Table 3. $\mathrm{Tb}(\mathrm{s})-\mathrm{RR}$ equations established by linear regression with least squares method.

\begin{tabular}{lllc}
\hline No & $\begin{array}{l}\text { TMI } \\
\text { Channel }\end{array}$ & \multicolumn{1}{c}{ Tb(s)-RR Equations } & $\begin{array}{c}\text { R } \\
\text { squared }\end{array}$ \\
\hline 1 & Tb1 & $\mathrm{RR}=-32.3756+0.18 \mathrm{~Tb} 1$ & 0.6581 \\
2 & $\mathrm{~Tb} 2$ & $\mathrm{RR}=-10.3739+0.0994 \mathrm{~Tb} 2$ & 0.6495 \\
3 & $\mathrm{~Tb} 3$ & $\mathrm{RR}=-33.8987+0.1509 \mathrm{~Tb} 3$ & 0.7255 \\
4 & $\mathrm{~Tb} 4$ & $\mathrm{RR}=-14.5571+0.0809 \mathrm{~Tb} 4$ & 0.7169 \\
5 & $\mathrm{~Tb} 5$ & $\mathrm{RR}=-71.0651+0.2801 \mathrm{~Tb} 5$ & 0.6467 \\
6 & $\mathrm{~Tb} 6$ & $\mathrm{RR}=-30.9012+0.1305 \mathrm{~Tb} 6$ & 0.5040 \\
7 & $\mathrm{~Tb} 7$ & $\mathrm{RR}=-11.8875+0.0606 \mathrm{~Tb} 7$ & 0.5000 \\
8 & $\mathrm{~Tb} 8$ & $\mathrm{RR}=43.3268-0.1536 \mathrm{~Tb} 8$ & 0.2828 \\
9 & $\mathrm{~Tb} 9$ & $\mathrm{RR}=34.1650-0.1220 \mathrm{~Tb} 9$ & 0.1932 \\
10 & $\mathrm{~Tb} 1-4$ & $\mathrm{RR}=-83.2263+0.5507 \mathrm{~Tb} 1-$ & 0.7552 \\
& & $0.2857 \mathrm{~Tb} 2+0.0124 \mathrm{~Tb} 3+0.0616 \mathrm{~Tb} 4$ & \\
11 & $\mathrm{~Tb} 1-5$ & $\mathrm{RR}=-73.7891+0.5294 \mathrm{~Tb} 1-$ & 0.7581 \\
& & $0.2780 \mathrm{~Tb} 2+0.0889 \mathrm{~Tb} 3+0.0449 \mathrm{~Tb} 4-0.0807 \mathrm{~Tb} 5$ & \\
12 & $\mathrm{~Tb} 1-6$ & $\mathrm{RR}=-53.9845+0.3817 \mathrm{~Tb} 1-$ & 0.7699 \\
& & $0.2006 \mathrm{~Tb} 2+0.0741 \mathrm{~Tb} 3+0.0726 \mathrm{~Tb} 4-0.0354 \mathrm{~Tb} 5-0.0602 \mathrm{~Tb} 6$ & \\
13 & $\mathrm{~Tb} 1-7$ & $\mathrm{RR}=-40.0423+0.4090 \mathrm{~Tb} 1-0.2160 \mathrm{~Tb} 2-$ & 0.7865 \\
& & $0.1904 \mathrm{~Tb} 3+0.2491 \mathrm{~Tb} 4-0.1128 \mathrm{~Tb} 5+0.1637 \mathrm{~Tb} 6-0.1162 \mathrm{~Tb} 7$ & \\
14 & $\mathrm{~Tb} 1-9$ & $\mathrm{RR}=-22.7097+0.4062 \mathrm{~Tb} 1-0.2149 \mathrm{~Tb} 2-$ & 0.7993 \\
& & $0.0259 \mathrm{~Tb} 3+0.1871 \mathrm{~Tb} 4-0.1957 \mathrm{~Tb} 5+0.0477 \mathrm{~Tb} 6-0.0803 \mathrm{~Tb} 7-$ & \\
& & $0.1371 \mathrm{~Tb} 8+0.1378 \mathrm{~Tb} 9$ & \\
\hline
\end{tabular}

during \#2961 ranging from 0.05 to $11.60 \mathrm{~mm} / \mathrm{hr}$. Figures $2 \mathrm{c}$ and $2 \mathrm{~d}$ show the TMI Tb1 and RR retrievals for \#2966, respectively. It is known that due to the differences between the low emisivity (about 0.5 ) of the ocean and the almost blackbody emission of precipitating rain, a warm $\mathrm{Tb}$ over the ocean represents a rainfall region. On the other hand, a high temperature over land is due to its emissions between about 0.9 and 1 . In this paper, for the purposes of filtering out the effects of coastlines where FOVs would be occupied partly by ocean and partly by land, the retrieval areas from the coastline to $20 \mathrm{~km}$ offshore are excluded.

From $00 Z 3$ June to $00 \mathrm{Z} 4$ June, a stationary Mei-Yu front system was over the Taiwan area. From the surface weather map for $00 Z$ on 3 June, it can be found that the Mei-Yu front stretched northeastward from Hainan, then crossed the middle of Taiwan, and finally formed an occluded front near Japan. At $12 \mathrm{Z}$ on 3 June, the western part of this Mei-Yu front stretched offshore from the southeast coast of China and then crossed the Taiwan Strait reaching the southern end of Taiwan. Finally, it stretched northeastward to Japan. At $00 \mathrm{Z}$ on 4 June, a stationary front again occurred over the middle of Taiwan. The front continued fluctuating northward or southward over Taiwan at this time, thus acting like a stationary front. According to Chiu et al. (1986), an MCS similar to the MCC defined by Maddox (1980) will move with the mean airflow between the $850 \mathrm{mb}$ and $200 \mathrm{mb}$ layers. However, a meso- $\beta$ scale MCS would be associated with shearing flow between the 300 and $850 \mathrm{mb}$ layers. If the MCSs are related to Mei-Yu fronts, their evolutions is greatly affected by the fronts. For MCSs that are 
Table 4. Use of 3 independent coincident $(T b, R R)$ pairs to quantitatively verify the Tb-RR equations.

\begin{tabular}{|c|c|c|c|c|c|c|}
\hline \multirow{2}{*}{$\begin{array}{l}\text { ITEM } \\
\text { No }\end{array}$} & \multicolumn{2}{|c|}{$\begin{array}{c}\text { Penghu } \\
\text { TRMM Orbit\#2730 } \\
\text { 1998/0519/23:56 } \\
\text { RR=0.5 mm/hr }\end{array}$} & \multicolumn{2}{|c|}{$\begin{array}{c}\text { Lanyu } \\
\text { TRMM Orbit\#2919 } \\
\text { 1998/0531/23:55 } \\
\text { RR=1.0 mm/hr }\end{array}$} & \multicolumn{2}{|c|}{$\begin{array}{c}\text { Tungchitao } \\
\text { TRMM Orbit\#3043 } \\
\text { 1998/0608/20:36 } \\
\text { RR=6.2 mm/hr }\end{array}$} \\
\hline & $\begin{array}{c}\text { Retrieved } \\
\text { RR' }\end{array}$ & RR'-RR & $\begin{array}{c}\text { Retrieved } \\
\text { RR' }\end{array}$ & RR'-RR & $\begin{array}{c}\text { Retrieved } \\
\text { RR' }\end{array}$ & RR'-RR \\
\hline 1 & 0.6202 & 0.1202 & 2.1124 & 1.1124 & 5.0194 & -1.1806 \\
\hline 2 & 0.8663 & 0.3663 & 1.9954 & 0.9954 & 5.0043 & -1.1957 \\
\hline 3 & 1.0422 & 0.5422 & 1.6926 & 0.6926 & 4.5491 & -1.6509 \\
\hline 4 & 0.9684 & 0.4684 & $1.55 \uparrow 7$ & 0.5517 & 4.6405 & -1.5595 \\
\hline 5 & 0.9066 & 0.4066 & 2.0466 & 1.0466 & 3.5591 & -2.6409 \\
\hline 6 & 1.5098 & 1.0098 & 2.1597 & 1.1597 & 3.1724 & -3.0277 \\
\hline 7 & 1.5257 & 1.0257 & 1.9572 & 0.9572 & 3.5704 & -2.6297 \\
\hline 8 & 3.3125 & 2.8125 & 0.1099 & -0.8901 & 5.0435 & -1.1565 \\
\hline 9 & 3.4076 & 2.9076 & 0.1831 & -0.8169 & 4.4665 & -1.7335 \\
\hline 10 & 0.1084 & -0.3916 & 1.9258 & 0.9258 & 4.7581 & -1.4420 \\
\hline 11 & 0.2847 & -0.2153 & 1.8938 & 0.8938 & 4.9899 & -1.2101 \\
\hline 12 & 0.3443 & -0.1557 & 1.6287 & 0.6287 & 5.2373 & -0.9627 \\
\hline 13 & 0.1767 & -0.3233 & 1.6178 & 0.6178 & 5.1591 & -1.0409 \\
\hline 14 & 0.1720 & -0.3280 & 1.9884 & 0.9884 & 5.4379 & -0.7621 \\
\hline
\end{tabular}

independent of Mei-Yu fronts, their movements are dominated by the upper level and $200 \mathrm{mb}$ level streamlines which are intimately related to their evolution (Chi and Chen 1988).

The GMS image data used in this paper were provided by the CSRSR (Center for Space and Remote Sensing Research at National Central University on Taiwan) and are shown in Fig. 3. The GMS IR enhanced image series runs from 12:32Z on 3 June to $02: 32 \mathrm{Z}$ on 4 June. Comparisons between the RR retrievals and the GMS IR images show that the TMI ninechannel Tbs-RR equation developed in this paper can indeed retrieve cloud clusters or MCS rainfall situations. For 15:32Z on 3 June, MCS\#1 to the west of Liuchiu, and MCS\#2 in the middle of the Bashi Channel are retrieved as heavy rainfall regions. For 23:32Z on 3 June, MCS\#3 offshore from the Guangdong Province of China, MCS\#4 to the east of Hainan, and MCS\#5 to the northeast of Luzon are also retrieved as rainfall regions. Apparently, MCS\#1 had been initiated near Taiwan. On the other hand, MCS\#3 and \#4 were typical weather systems coming from southern China. MCS\#2 was a typical stationary MCS over the Bashi channel in this season, which could have resulted from southwesterly moist winds that prevail over the South China Sea and from different convective systems, such as MCS\#1, \#3, and \#4. MCS\#5, on the other hand, perhaps is related to the orographic features of Luzon, the summer monsoon, and the Mei-Yu front.

There have been many attempts in the past to estimate correlation between cloud top IR Tb and convective rainfall. Arkin(1979) used 6-hr rainfall amounts to be rainfall ground truth during the Global Atmospheric Research Program (GARP) Atlantic Tropical Experiment (GATE). A linear relationship between the 6-hr mean fractional cloud cover colder than the selected IR rain threshold and the 6 -hr mean rainfall accumulations is established. An IR Tb 
indicates a specific height and a cloud fractional coverage within which the cloud temperature is colder than this selected IR Tb. According to GATE sounding profiles, the maximum correlation (larger than 0.8 ) was found at $235 \mathrm{~K}$ (at an altitude of $10 \mathrm{~km}$ ), for a zero time lag between the satellite and radar observations. About $75 \%$ of the variance in the GATE rainfall as estimated from radar observations was explainable as a linear function of the cloud top IR Tb being colder than 235K. Furthermore, Arkin and Meisner (1987) used a simple thresholding technique (GPI, Geostationary Operational Environment Satellite (GOES) Precipitation Index) to estimate the spatial and temporal averaged convective precipitation from GOES satellite IR data. They found that tropical convective rainfall was best estimated using a threshold of $235 \mathrm{~K}$, while in the extratropics a threshold of 220K was best. Kummerow and Giglio (1995) combined data from GMS IR data, SSM/I MW, radar, and surface rain gauges to find the variable rainfall threshold over Darwin, Australia. They found that rainfall over the Darwin region would be best correlated with a mean threshold of approximately GMS IR Tb $210 \mathrm{~K}$.

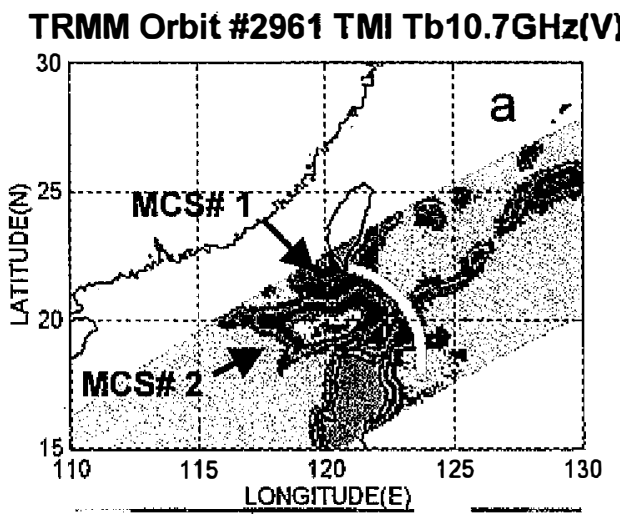

$\begin{array}{llllllllll}100 & 180 & 185 & 190 & 200 & 210 & 220 & 230 & 240 & 260\end{array}$

TRMM Orbit \#2966 TMI Tb10.7GHz(V)

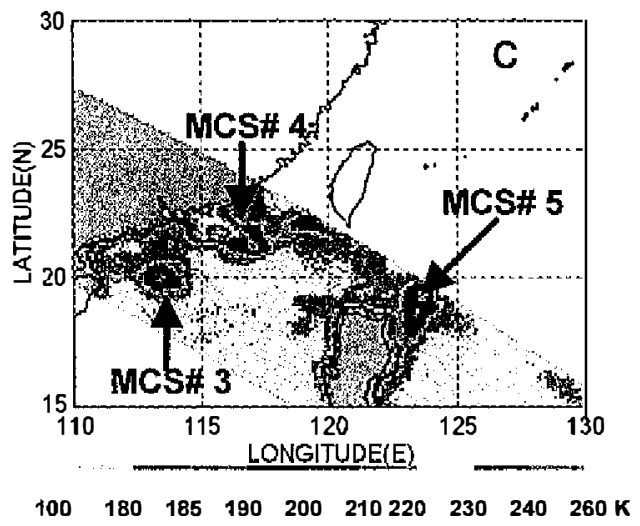

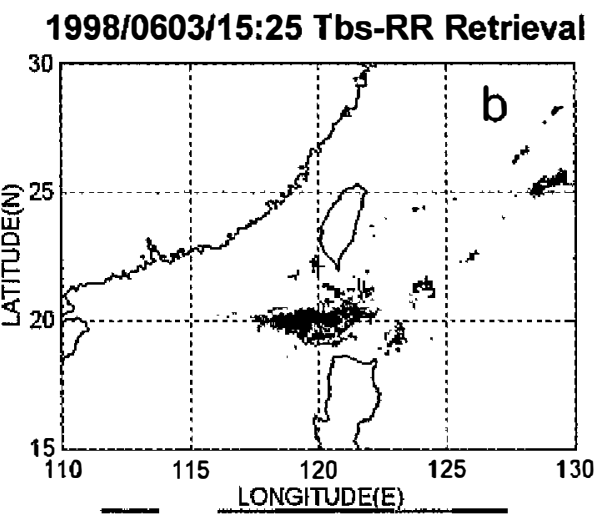

$\begin{array}{lllllllll}0 & 1 & 3 & 5 & 7 & 9 & 11 & 11.60 & \mathrm{~mm} / \mathrm{hr}\end{array}$

1998/0603/23:29 Tbs-RR Retrieval

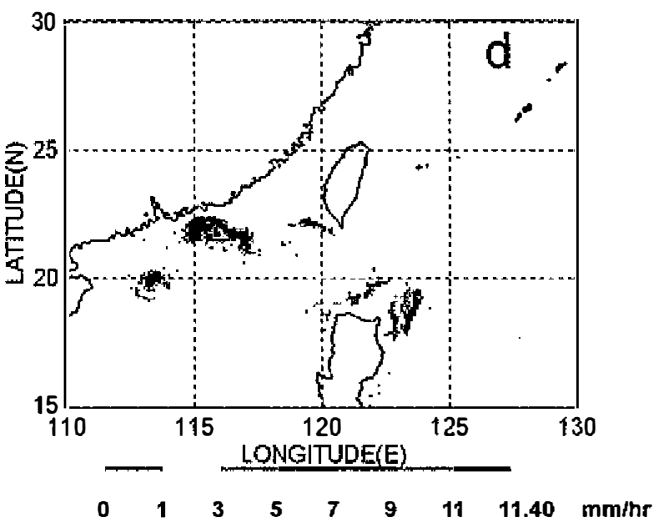

Fig. 2. TMI $10.7 \mathrm{GHz}(\mathrm{V}) \mathrm{Tb}$ and oceanic $\mathrm{RR}$ retrievals from orbit \#2961 (a and b), and from orbit \#2966 (c and d). 

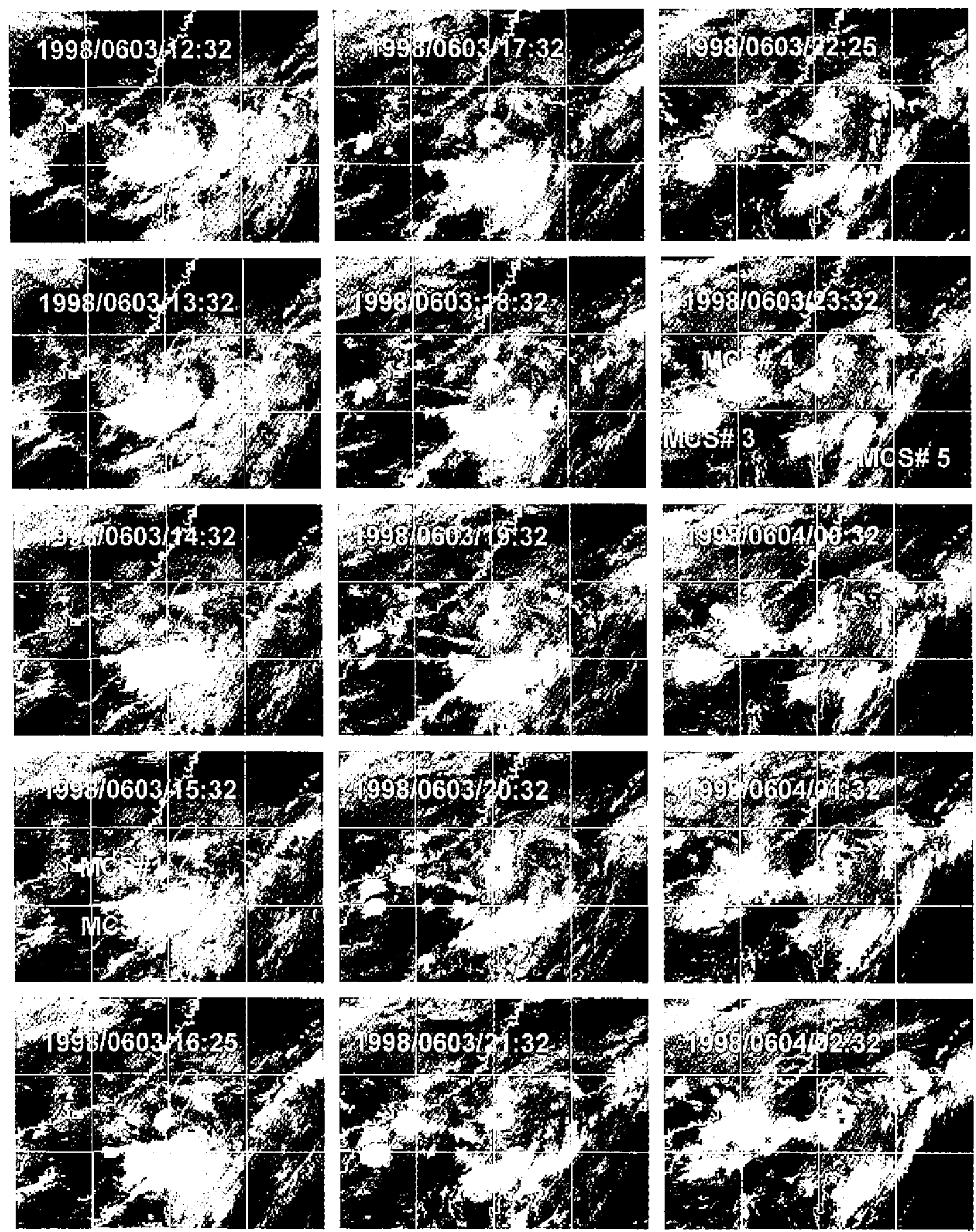

Fig. 3. GMS infrare image series from $12: 32 Z$ on 3 June to $02: 32 Z$ on 4 June. 
Moreover, Maddox (1980) defined the life stages of a mesoscale convective complex by the changes and variations in IR $\mathrm{Tb}$ isotherms at $-50^{\circ} \mathrm{C}$ and $-30^{\circ} \mathrm{C}$ (about $220 \mathrm{~K}$ and $240 \mathrm{~K}$ ). Based on their research, the rainfall accumulation could be explained as a linear function of cloud top coverage colder than the selected IR Tb threshold. Here, we superimpose the GMS IR Tbs for the $210 \mathrm{~K}, 220 \mathrm{~K}, 240 \mathrm{~K}$ isotherms onto the TMI oceanic RR retrievals in order to analyze the relationship between IR Tbs and rainfall distributions.

At 15:25Z on 3 June, the TRMM satellite moved northeastward from the central South China Sea to the north of the South China Sea and then crossed the Bashi Channel, Luzon, and finally southem Taiwan. This orbit was \#2961. Figure 4 shows the details of the MCS\#1 and MCS\#2 RR retrievals. By using the Tbs-RR equation established above, a maximum RR of $11.6 \mathrm{~mm} / \mathrm{hr}$ was retrieved during MCS\#2. The GMS IR Tb $210 \mathrm{~K}, 220 \mathrm{~K}$, and $240 \mathrm{~K}$ isotherms are also plotted in the same figure. The observation time for the GMS IR data was 15:32Z on 3 June. We tried to analyze the relationship between the TMI retrieved rainfall regions and the GMS IR Tb isotherms.

In Fig. 3, we see the first MCS\#1 observation taken at 14:32Z on 3 June to the west of Liuchiu, which merges with clouds from the north at $21: 32 \mathrm{Z}$ on 3 June. It occupied the southern Taiwan area, continuously affecting this region for more than 12 hours. As shown in Fig. 4 , the MCS\#1 rainfall region could be included by the $240 \mathrm{~K}$ isotherm. However, the area under this cold cloud has both rainy and non-rainy portions, even though there was an area under very cold cloud where the IR Tb was lower than $210 \mathrm{~K}$. The non-rainy region lay under the rear part of the MCS, while the rainfall region was concentrated on the forward side of the MCS, in the direction of movement. A heavy rainfall region with RR larger than about $6 \mathrm{~mm} /$ hr might be included by the $210 \mathrm{~K}$ isotherm, while the maximum $\mathrm{RR}, 9.5 \mathrm{~mm} / \mathrm{hr}$, was observed beside the $210 \mathrm{~K}$ isotherm in the forward part of the MCS.

In Fig. 3, at 12:32Z on 3 June, MCS\#2 had already existed over the Bashi Channel between Taiwan and Luzon. By $21: 32 Z$, it had dissipated and merged with frontal clouds moving northeastward. As in MCS\#1, the MCS\#2 rainfall regions could be included by the IR Tb $240 \mathrm{~K}$ isotherms. The rain region was concentrated in the northeastern portion of the MCS\#2. MCS\#2 moved northeastward due to the seasonal environmental circulation. Heavy rainfall occurred on both sides of the $210 \mathrm{~K}$ isotherm. The maximum RR of $11.6 \mathrm{~mm} / \mathrm{hr}$ was retrieved inside the $210 \mathrm{~K}$ isotherm. Outside the $210 \mathrm{~K}$ isotherm, where it was colder than $220 \mathrm{~K}$, an RR of $9.2 \mathrm{~mm} / \mathrm{hr}$ was also retrieved. Therefore, we note that heavy rain events occurred in the forward portion of MCS\#2, beside the $210 \mathrm{~K}$ isotherm, and that there was no rain in the rear part, even though its IR Tb was lower than 210K. IR images show that MCS\#2 included two cold cloud regions, colder than $210 \mathrm{~K}$. However, in Fig. $2 \mathrm{~b}$, there is only one warm MW Tbl region at this same place. Viewing Fig. 3, observed at $12: 32 \mathrm{Z}$ and $13: 32 \mathrm{Z}$, there are no two obvious convective zones over the Bashi Channel. Until 14:32Z, there are two cold cloud regions in MCS\#2. Since there is only one rainfall region, and MCS\#1 was also first observed in the vicinity of Liuchiu at that time, the environment over this region should thus have been very favorable for the formation and organization of MCSs. The second cold cloud region should indicate a new convective system or a dissipating system with a life cycle of less than 1 hour.

The TRMM satellite flew southeastward from southern China over the north of the South 


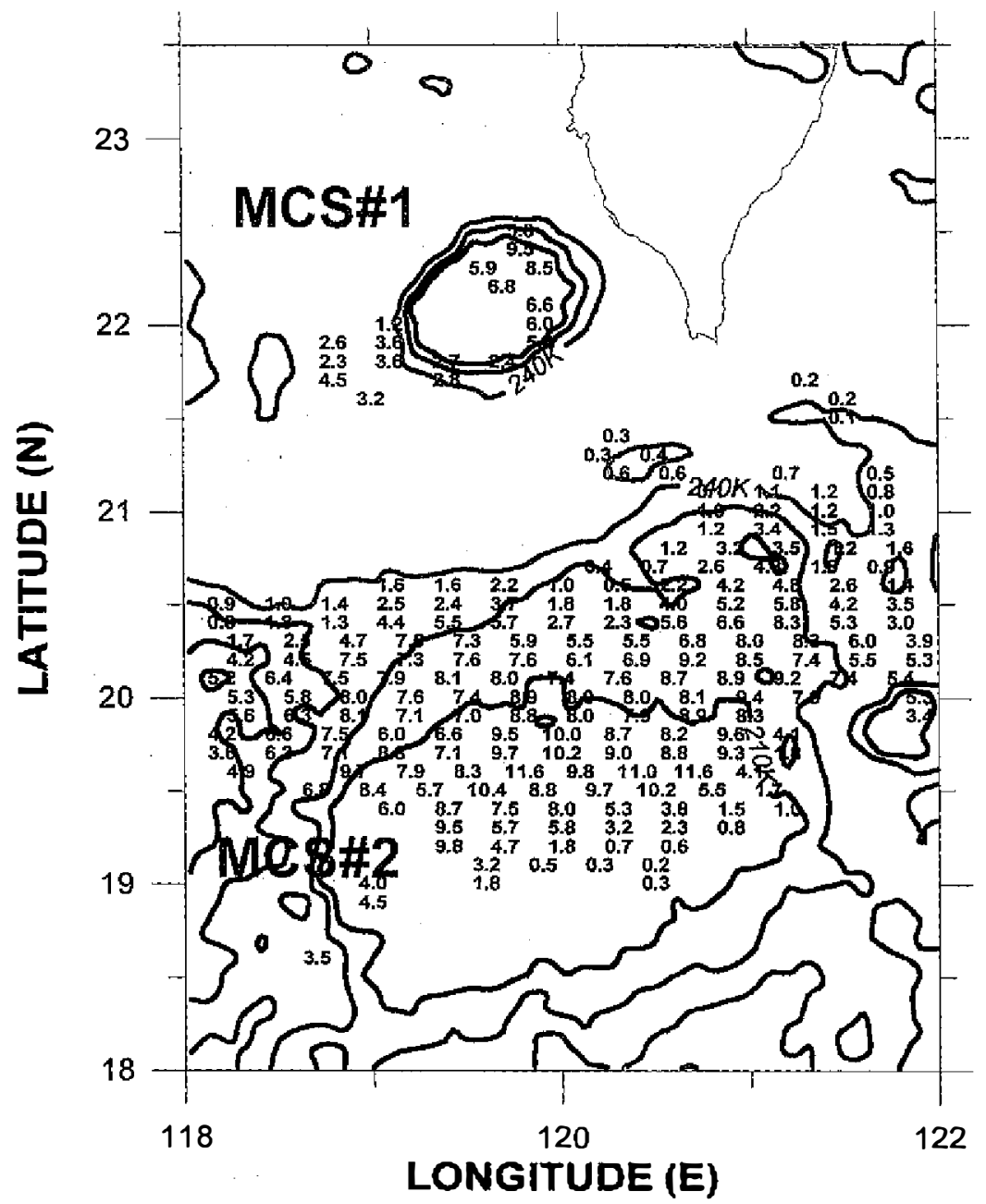

Fig. 4. RR(mm/hr) retrieved by TMI Tbs at $15: 25 \mathrm{Z}$ on 3 June 1998 . The contour lines are the GMS IR $210 \mathrm{~K}, 220 \mathrm{~K}$ and $240 \mathrm{~K}$ isotherms, at 15:32Z on 3 June 1998.

China Sea and Luzon at 23:29Z on 3 June. The TMI Tbs retrieved RRs of MCS\#3 and \#4 and \#5. The GMS IR Tb isotherms $(210,220,240 \mathrm{~K})$, for $23: 32 Z$ on 3 June, are shown in Figs. 5 and 6, respectively. A rainfall maximum of $11.4 \mathrm{~mm} / \mathrm{hr}$ was retrieved within MCS\#3, located offshore from the south China coast. The maximum rain rates within MCS\#3,4 and 5 all exceed $7 \mathrm{~mm} / \mathrm{hr}$, and the retrieved rainfall regions were all located under cloud clusters. The MCS\#3 rainfall pattern was the same as for MCS\#1 and \#2. Rainfall regions fell in the forward portion of the MCS to the east. The rainfall maximum was retrieved beside the $210 \mathrm{~K}$ isotherm.

However, the MCS\#4 rainfall pattern was quite different from MCS\#1, 2, and 3. MCS\#4 was first observed on the coast of southern China at 17:32Z on 3 June (see Fig. 3). At 20:32Z, it became weaker and moved southwards. At 23:32Z, it merged with another cloud cluster 
which had developed to the east of Hainan at 19:32Z. By 00:32Z on 4 June, it had weakened and combined with another prefrontal systems. Thus, at 23:29Z on 3 June, MCS\#4 was already at the end of its mature stage. Within MCS\#4, the area enclosed by the $210 \mathrm{~K}$ isotherms was very small. As in MCS\#1,2 and 3, its rainfall regions were in the forward part of the system to the east. As for the western part of this system, no rainfall was retrieved. However, the MCS\#4 rainfall maximum, only about $7.4 \mathrm{~mm} / \mathrm{hr}$, did not fall inside the $210 \mathrm{~K}$ isotherm, but in the region between the 210 and $220 \mathrm{~K}$ isotherms. For the region inside the $210 \mathrm{~K}$ isotherm, rainfall amounts were less than $3 \mathrm{~mm} / \mathrm{hr}$. For an MCS at the end of its mature stage, the intensity of the RR maximum would be weaker and the fraction of the $210 \mathrm{~K}$ coverage would be smaller than those of a developing MCS like MCS\#3. Nevertheless, the rainfall region would still be located on the forward side of its movement. In addition, the location of the RR maximum reveals that when an MCS is at the end of its mature stage clouds colder than $210 \mathrm{~K}$ cannot indicate heavy rainfall.

MCS\#5 looked like a stationary MこS offshore and to the northeast of Luzon. However, it could not be judged from the GMS IR Image series with certainty. According to Fig. 3, a cloud cluster existed in this region at 21:32Z on 3 June. This did not change location but continued to grow. It became most compact when the TRMM satellite moved across this region, including two cold clouds with temperatures lower than $210 \mathrm{~K}$. A rainfall maximum of $9.1 \mathrm{~mm} / \mathrm{hr}$ was located in the north-northeastern part of the MCS, which was the place with the highest temperature gradient. In the east of the MCS, the RRs were greater than $5 \mathrm{~mm} / \mathrm{hr}$. Moreover, in the southern part of the system, there was another cold cloud with temperatures lower than $210 \mathrm{~K}$ and a larger area. The retrieved rainfall maximum $(8 \mathrm{~mm} / \mathrm{hr})$ was beside the $210 \mathrm{~K}$ isotherm. Heavy rainfall with an RR larger than $7 \mathrm{~mm} / \mathrm{hr}$ was retrieved in the southeastern part of the

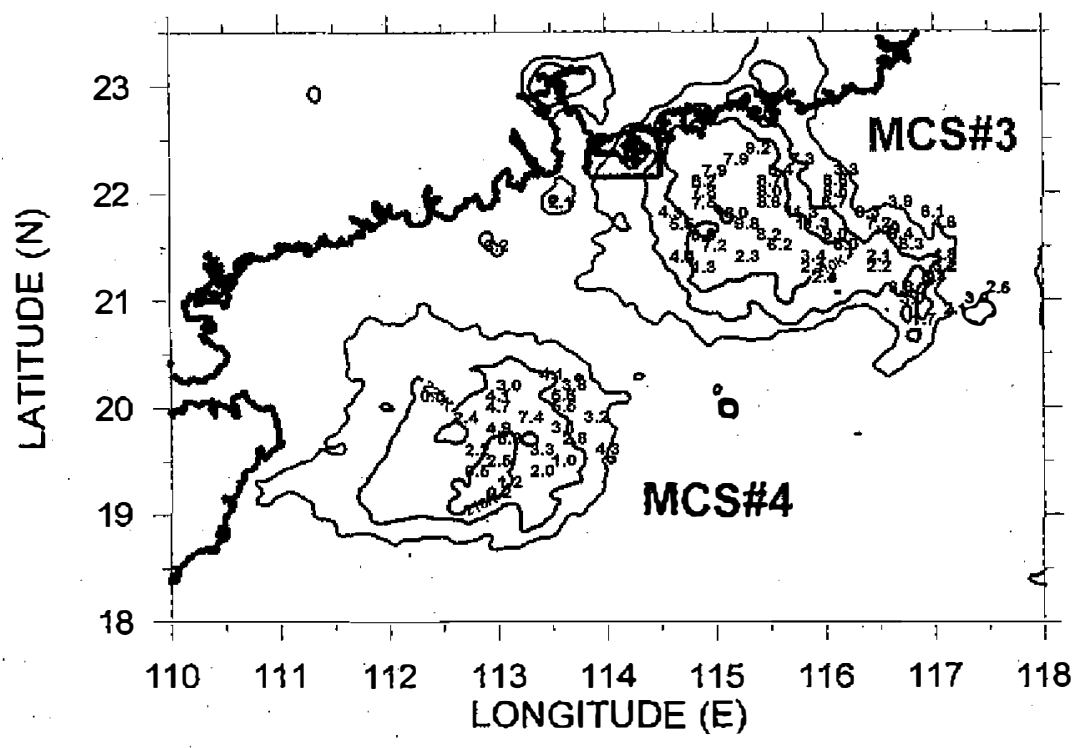

Fig. 5. The retrieved RRs from MCS\#3 and MCS\#4. The TMI time is 23:29Z and the GMS time is $23: 32 Z$. 


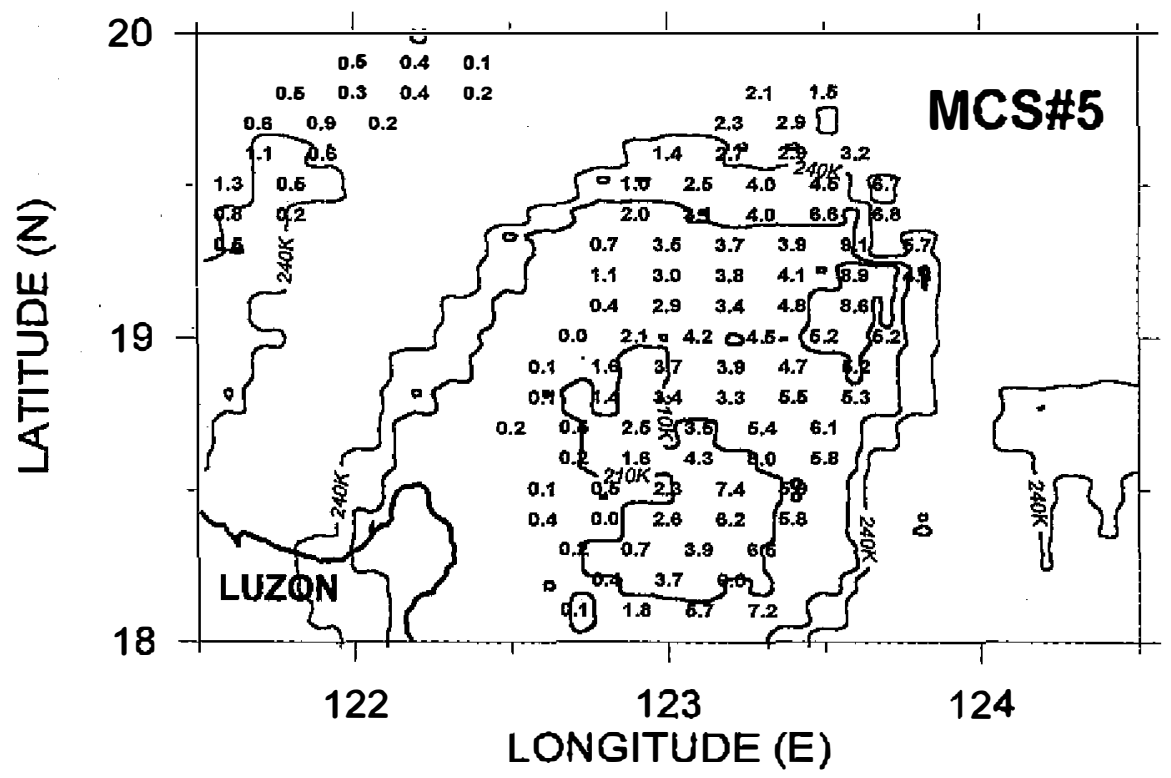

Fig. 6. As in Fig. 5, but the retrieved RRs are from MCS\#5.

area; which is enclosed by the $210 \mathrm{~K}$ isotherm. As mentioned above, there was heavy rainfall in the forward part of the MCS. Therefore, the first cold cloud moved to the north-northeast while the second tended to move eastward. As seen in Fig. 3, from 00:32Z to 02:32Z the movement of MCS\#5 was dominated by the Mei-Yu front. It moved north-northeastward and southeastward at the same time and then merged into the Mei-Yu front moving northeastward towards Okinawa.

The IR rainfall threshold is related to the location. For global usage, IR $\mathrm{Tb} 235 \mathrm{~K}$ is usually used to represent rain region (Arkin and Meisner 1987). However, here, the rainfall regions were concentrated in the forward portions of the MCS in its direction of movement. No matter how cold it was, no rainfall was observed under cloud cover in the rear part of the MCS. Thus, IR remote sensing is an indirect method and simply provides the cloud top information. Unlike MW which has very good transmissivity through cloud, IR can't penetrate the cloud and sense the precipitation directly. Moreover, the MCS\#2 analysis reveals that using GMS IR isotherms to define the life stages of the MCS and the rainfall commencement threshold, for the purpose of predicting rainfall intensity and amount, might lead to unavoidable errors.

The IR equipment on satellites can provide data with a temporal resolution of at least one hour. Nevertheless, using the IR technique to estimate rainfall measurements is an indirect method and might be misled by cirrus clouds, for example. On the other hand, MW is a better remote sensing technique to estimate oceanic RRs. However, at present MW radiometers on satellites cannot provide data with enough temporal resolution for mesoscale weather analysis; otherwise this would be a good way to predict heavy rainfall. Therefore, techniques combining MW with IR satellite data will improve prediction of heavy rainfall caused by MCSs or other weather systems. 


\section{A CASE STUDY OF RAINFALL ENHANCEMENT}

Two-thirds of Taiwan is covered by rugged terrain leading to well-known local rainfall enhancement in this region (Chen and Yu 1990; Lin 1993). This enhancement, in conjunction with a number of factors, could cause flash flooding. Such factors are local orographic effects, the cyclonically curved coastal line of southern Taiwan, the effects of the topographic flow blocking on the formation and maintenance of a mesolow, the convergence of the prevailing southwesterly winds, and impinging mesoscale weather systems. Since most of severe convective systems come from ocean, the oceanic $R R$ distributions retrieved by the Tbs-RR equation should contribute most helpfully to the prediction of heavy rainfall and a better understanding of the influence of orographic effects on rainfall distribution over both sea and land. As mentioned above, techniques with fusion of MW and IR data would be a good method to analyze MCSs and to improve heavy rainfall forecasting. In this paper, we monitor MCS\#1 and its evolution to understand how it influences the rainfall pattern over both ocean and land in southern Taiwan. The data sets used here included RRs retrieved from TMI/MW Tbs, GMS/ IR data, and rain gauge data from both observatory and rain gauge networks. Figures $7 \mathrm{a}-\mathrm{g}$ show, from 15:32Z to 23:32Z on 3 June, the GMS IR Tb contours and rainfall distributions of both land and ocean areas in the vicinity of southern Taiwan. Table 5 shows the rainfall records from 26 stations located in southern Taiwan (south of $23.33^{\circ} \mathrm{N}$ ) from 16 to $24 \mathrm{Z}$, on 3 June. This table also reveals rainfall distribution and variation information.

MCS\#1 was first observed at 14:32Z to the west of Liuchiu (Fig. 3). Since there were no TMI observations at this time, it was difficult to ascertain the amount of rainfall over the ocean. According to the GMS IR image, MCS\# 1's rainfall intensity could be roughly predicted by the area approximately enclosed by the $220 \mathrm{~K}$ and $240 \mathrm{~K}$ isotherms. Until 15:25Z, TRMM flew across this region and quantitative rainfall distributions were rerieved. The GMS satellite observed the same region as the TRMM had at 15:32Z. In addition to the RR retrievals and the GMS IR contours, Figure 7 also includes the accumulated hourly rainfall observations from southem Taiwan and the surrounding islands, as measured by rain gauges. In order to filter out the coastal effect on the MW Tbs, there were no oceanic RR retrievals within 20 $\mathrm{km}$ of the coast. From left to right, the $\boldsymbol{\Delta}$ symbols stand for Liuchiu, Hengchun, Lutao, and Lanyu, respectively.

As shown in Fig. 7a, at 16Z, there was no rain on southern Taiwan. The retrieved RR maximum was $9.5 \mathrm{~mm} / \mathrm{hr}$ and most of the RRs inside the $210 \mathrm{~K}$ isotherm were greater than 5 . $5 \mathrm{~mm} / \mathrm{hr}$. The rainfall region was concentrated in the eastern part of MCS\#1 which tended to move eastward, affecting southern Taiwan. Liuchiu was not covered by MCS\#1, and since there was no rain on Liuchiu, this means that MCS\#1 did not yet affect Liuchiu at that time.

At 16:25Z, the $240 \mathrm{~K}$ isotherm reached the coast of southern Taiwan (Fig. 7b). Liuchiu, with an RR of $0.5 \mathrm{~mm} / \mathrm{hr}$ was located inside the $220 \mathrm{~K}$ isotherm. MCS\#1 was still located offshore, and thus no rain was observed over southern Taiwan at this time. Until 17:32Z, the $240 \mathrm{~K}$ isotherm moved into southern Taiwan, and the $220 \mathrm{~K}$ line lay in the region between the plains and the hills (Fig. 7c). As for the $210 \mathrm{~K}$ isotherm, it moved into southern Taiwan where an RR of $10 \mathrm{~mm} / \mathrm{hr}$ was observed in the coastal region. Meanwhile, the RR observed at Liuchiu was $6 \mathrm{~mm} / \mathrm{hr}$. The range of RR within the region between $210 \mathrm{~K}$ and $220 \mathrm{~K}$ was ranged from 0 . 
Table 5. The hourly accumulated rainfall records from 26 stations to the south of $23.33^{\circ} \mathrm{N}$ over southern Taiwan (light dashed shading means no rain and dark dashed shading means RR larger than $30 \mathrm{~mm} / \mathrm{hr}$ ).

\begin{tabular}{|c|c|c|c|c|c|c|c|c|c|}
\hline Stations\& Time & $16 Z$ & $17 Z$ & $18 Z$ & $19 Z$ & $20 Z$ & $21 Z$ & $22 Z$ & $23 Z$ & $24 Z$ \\
\hline iuchiu (120.35E, 22.33N) & 04 & 80013 & 6.0 & 1.0 & 0.5 & 1.0 & 0.5 & 0.5 & 0.5 \\
\hline Maopitao(120.73E, 21.92N) & $0 \%$ & & 8.5 & 8.5 & 5.0 & 2.5 & $100 \%$ & & 3.0 \\
\hline Checheng(120.71E, $22.08 \mathrm{~N})$ & & & 18.5 & 9.0 & 15.5 & 7.5 & & 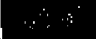 & 5.5 \\
\hline Pinlang (120.83E, 22.08N) & & & 1.5 & 7.0 & 8.5 & .0 & & $r$ & 2.5 \\
\hline Fungkang $(120.68 \mathrm{E}, 22.19 \mathrm{~N})$ & & & 14.0 & 15.0 & 15.5 & 6.5 & & & 8.5 \\
\hline Mutan (120.83E, 22.19N) & & & 709 & 17.0 & 10.5 & 7.5 & 00 & & 3,0 \\
\hline Hsuhai $(120.88 \mathrm{E}, 22.20 \mathrm{~N})$ & & & 60 & 13.5 & 6.5 & 6.5 & 1606 & - & 1.0 \\
\hline$E, 22.24 N)$ & & & 10 & 1.0 & 1.0 & 3.5 & & & 2.5 \\
\hline $65 \mathrm{E}, 22.25 \mathrm{~N})$ & & & $7: 0$ & 28.0 & 11.0 & 11.5 & & 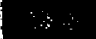 & 12.0 \\
\hline $8 \mathrm{E}, 22.37 \mathrm{~N})$ & & & 6.0 & 23.5 & 11.0 & 11.5 & & $\therefore$ & \\
\hline $.51 \mathrm{E}, 22.49 \mathrm{~N})$ & & & 3.0 & 10.0 & 24.5 & 14.5 & 23.5 & $\therefore$ & 14.0 \\
\hline $22.53 \mathrm{~N})$ & & & 2.0 & 16.0 & 9.0 & 9.0 & 10.5 & 19 & 17.5 \\
\hline $38 \mathrm{E}, 22.54 \mathrm{~N})$ & & & 10.0 & 20.5 & 23.5 & 27.5 & & 22.5 & 0.5 \\
\hline$(42 \mathrm{E}, 22.61 \mathrm{~N})$ & & & 5.5 & 18.0 & 14.5 & 16.5 & 4 & 9.0 & 7.0 \\
\hline $0.35 \mathrm{E}, 22.65 \mathrm{~N})$ & & & 0.5 & 16.5 & & & 22.5 & 2.0 & 00 \\
\hline $0.29 \mathrm{E}, 22.68 \mathrm{~N})$ & & & 0.5 & 18.0 & & 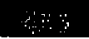 & 11.0 & 3.0 & 0 \\
\hline Fenshyon(120.34E, 22.75N) & & & & 6.0 & $\therefore$ & 22.0 & 12.5 & 20.0 & $1 \%$ \\
\hline $.29 \mathrm{E}, 22.76 \mathrm{~N})$ & & & (4) & 15.0 & 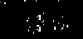 & 7.5 & 9.5 & 15.5 & \\
\hline $4 \mathrm{E}, 22.81 \mathrm{~N})$ & & & 00 & 2.0 & is & 16.0 & 8.5 & 8.0 & 0.5 \\
\hline $282 \mathrm{~N}$ & & & & 1.5 & 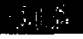 & 23.0 & 7.0 & 8.5 & 0.5 \\
\hline Sanye $(120.36 \mathrm{E}, 22.84 \mathrm{~N})$ & & & & 5.0 & 29.5 & 10.0 & 0.5 & 0.5 & 0.5 \\
\hline Meinong $(120.51 \mathrm{E}, 22.9 \mathrm{~N})$ & & & & $20 \%$ & 5.5 & 21.0 & 13.0 & 14.5 & 2.5 \\
\hline $20.55 \mathrm{E}, 22.97 \mathrm{~N})$ & & & & 0.5 & 1.0 & 16.5 & 14.5 & 9.5 & 1.0 \\
\hline Shinshih $(120.29 \mathrm{E}, 23.06 \mathrm{~N})$ & & & & & 0.5 & 1.0 & 0.5 & 16 & 20 \\
\hline $71 \mathrm{E}, 23.13 \mathrm{~N})$ & & & & & & 10.5 & 16.5 & 24.0 & 14.5 \\
\hline aiho $(120.42 \mathrm{E}, 23.33 \mathrm{~N})$ & & & & & & $00 \%$ & 0.5 & 0.5 & Wh \\
\hline
\end{tabular}

5 to $7 \mathrm{~mm} / \mathrm{hr}$ on the plain. For the windward slopes of the Hengchun Peninsula, inside the $240 \mathrm{~K}$ isotherm, the RR could be up to $18.5 \mathrm{~mm} / \mathrm{hr}$ at this time. However, there was no rain on the lee wind slopes of the peninsula or in eastern Taiwan. Apparently, MCS\#1 did not climb over the central mountain range (CMR) at this time. The rainfall enhancement might have been a result of the effects of topographic flow blocking or orographic lifting.

At 18:32Z, the rainfall regions included both the plains and the mountains of southwestern Taiwan and the whole Hengchun Peninsula. The $220 \mathrm{~K}$ and $240 \mathrm{~K}$ isotherms had moved northward about $30 \mathrm{~km}$. The $210 \mathrm{~K}$ isotherm moved back to the coastline and no longer existed over southem Taiwan. On the other hand, the $240 \mathrm{~K}$ isotherm moved further into the mountain region and was present to the west of the CMR. Liuchiu, with an RR of $1 \mathrm{~mm} / \mathrm{hr}$ was located right on the $210 \mathrm{~K}$ isotherm at this time. Thus, it was not in the forward portions of MCS\#1. RRs on the Hengchun Peninsula were larger in the north than in the south, while those in the east were about the same as in the west. RRs of $17,15,9$, and $7.5 \mathrm{~mm} / \mathrm{hr}$ were observed for the eastern, western, northern and southem parts of the Hengchun Peninsula, respectively. At this time, southern Taiwan was located in the forward part of MCS\#1. The strength of rainfall was obviously enhanced by the orographic effects and was related to changes in the $220 \mathrm{~K}$ and $240 \mathrm{~K}$ isotherms. The heavy rainfalls observed in the coastal areas revealed that the curved 
coastline might have contributed to local rainfall enhancement.

At 19:32Z, MCS\#1 combined with another MCS from the north. The $220 \mathrm{~K}$ isotherm moved onto land, climbed over the CMR and the Hengchun Peninsula, then reached the eastem coast of Taiwan. On eastern Taiwan, it started to rain (Fig. 7d). Meanwhile, a cold cloud, enclosed by the $210 \mathrm{~K}$ isotherm, appeared over the ocean to the west of MCS\#1. The RR strength at Checheng was obviously affected by the evolution of the $220 \mathrm{~K}$ isotherm. At 17 : $32 \mathrm{Z}$ and 19:32Z, Checheng located in front of the $220 \mathrm{~K}$ isotherm with an $\mathrm{RR}$ reaching more than $15 \mathrm{~mm} / \mathrm{hr}$. However, at $18: 32 \mathrm{Z}$, the $220 \mathrm{~K}$ isotherm moved backward and the RR became $9 \mathrm{~mm} / \mathrm{hr}$. On the plain, heavy rains were observed in the forward portion of MCS\#1, which were related to the evolution of the $210 \mathrm{~K}$ isotherm.

MCS\#1 separated into two parts at 21:32Z (Fig. 7e). Except for the most southern part of Taiwan, no rainfall was reported for the Hengchun Peninsula or on the eastern side of Taiwan. Thus, the rainfall region had already moved back to the west of the CMR at this time. Rainfall observations near the western coast reached $73.5 \mathrm{~mm} / \mathrm{hr}$. Since the strength of MCS\#1 was not enough to climb over the CMR, the effect of topographic flow blocking on the formation and maintenance of the mesolow could explain the heavy rainfall that occurred inside the $210 \mathrm{~K}$ isotherm. The heaviest rainfall region had a tendency to move southward.

At 22:25Z, the rainfall region covered the whole of southern Taiwan (Fig. 7f). There were four regions enclosed by $210 \mathrm{~K}$ isotherms at this time. The heaviest rainfall area was located on the junction of the plain in southern Taiwan and the mountains of the Hengchun Peninsula.

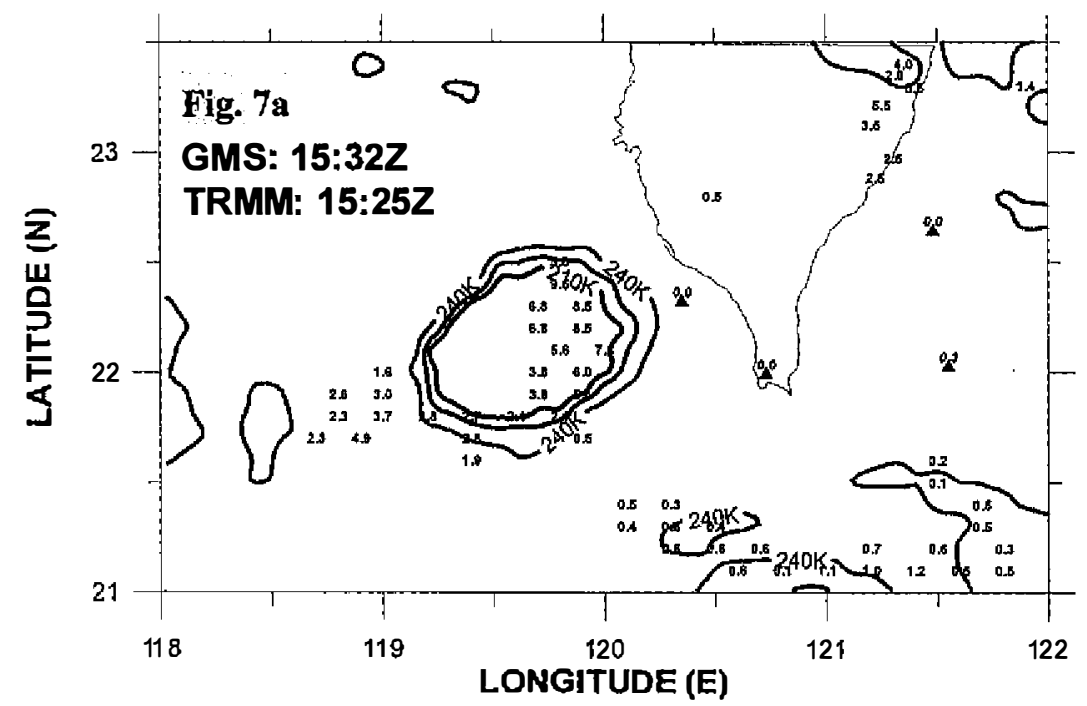

Fig. 7a-g. TRMM MW Tbs retrieved oceanic RR superimposed upon GMS IR $\mathrm{Tb} 210 \mathrm{~K}, 220 \mathrm{~K}$ and $240 \mathrm{~K}$ isotherms. The data marked on land and islands stand for rain gauge RRs measured by the Taiwan Central Weather Bureau. The $\boldsymbol{\Delta}$ symbols, from left to right, stand for Liuchiu, Hengchun, and Lutao. TRMM flew across this region only at 15:25Z and 23:29Z in this study. 

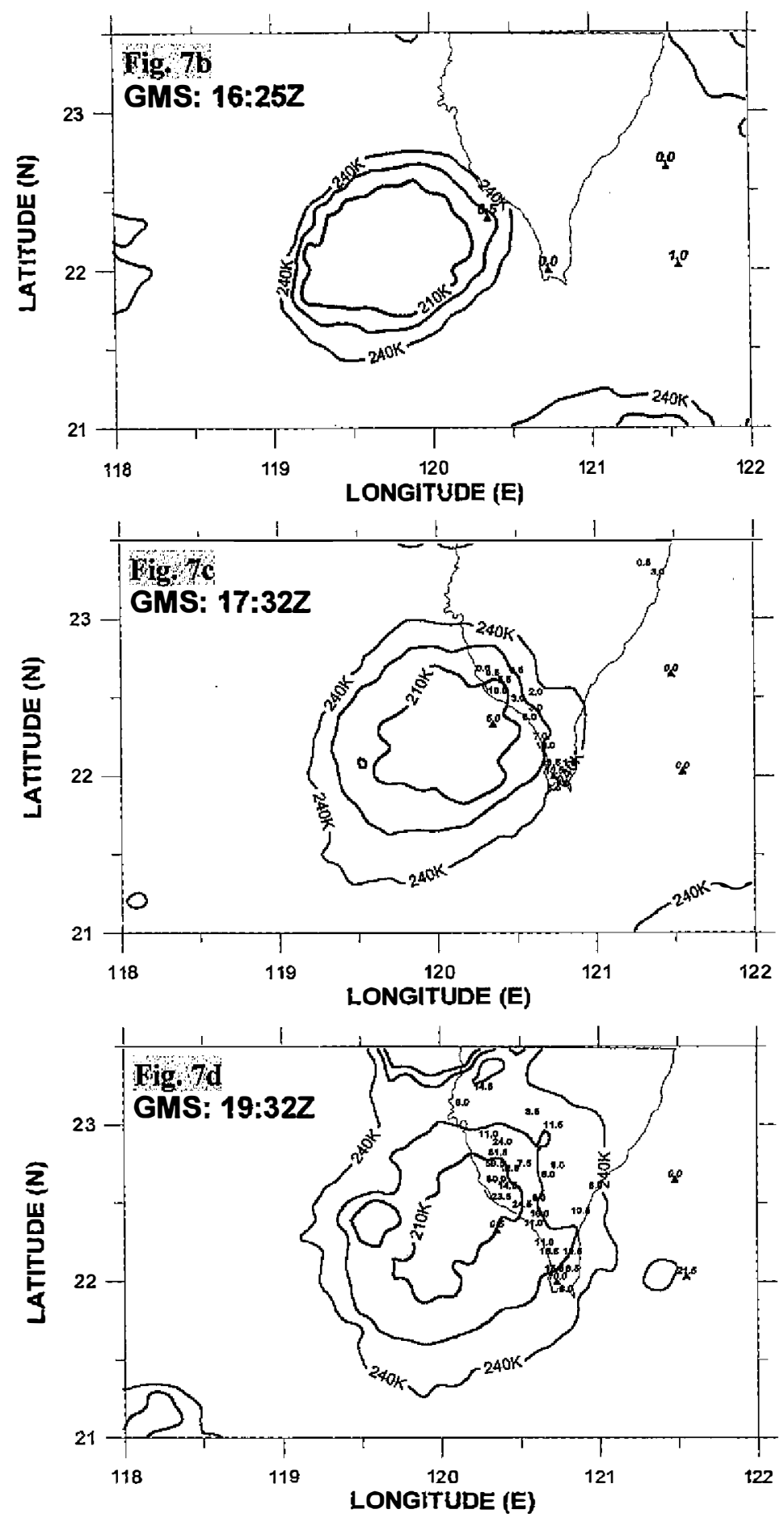

(Fig. 7. continued) 

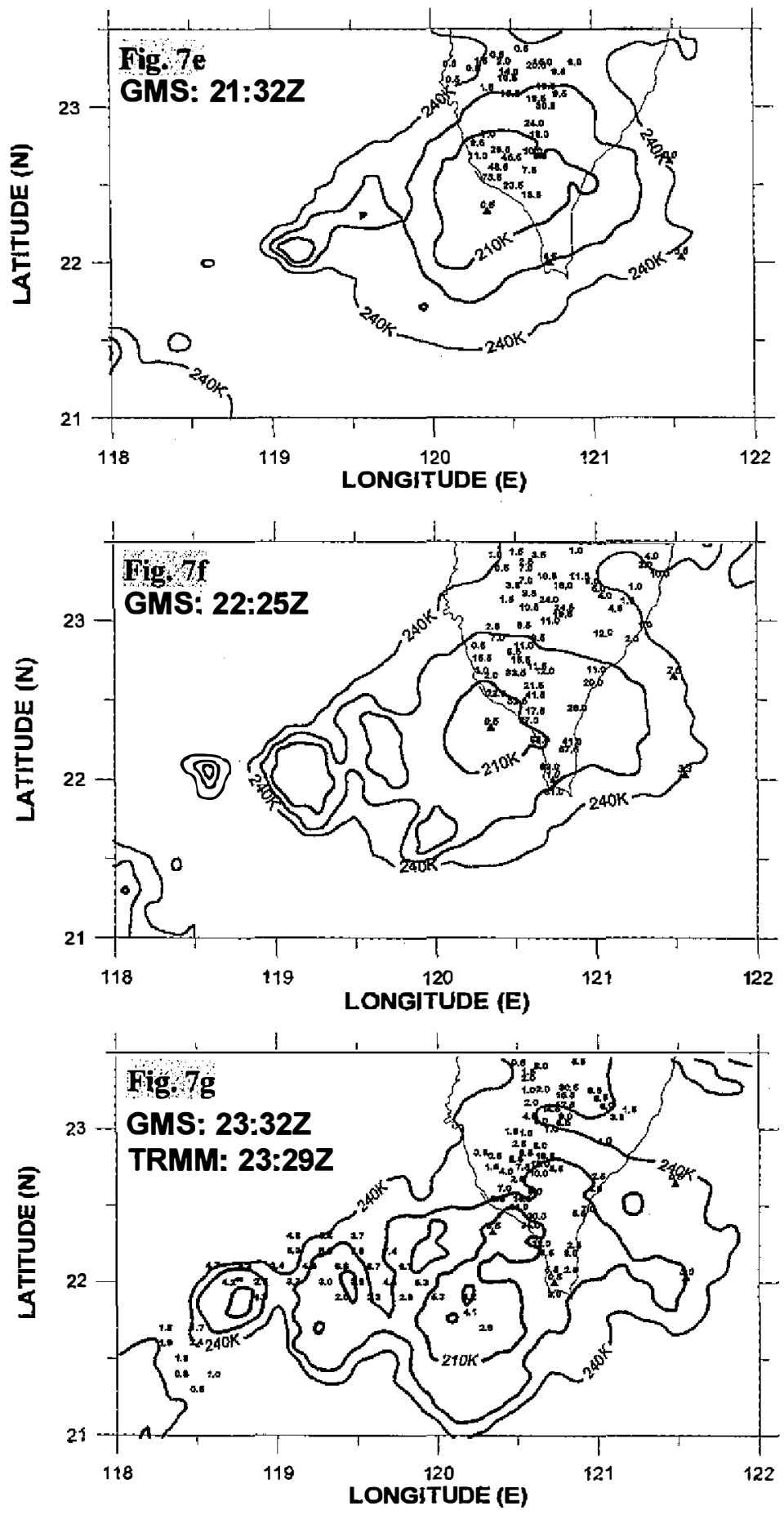

(Fig. 7. continued) 
The heaviest rainfall was located right beside the $210 \mathrm{~K}$ isotherm (Fangliao/77 and Fangshan/ $68 \mathrm{~mm} / \mathrm{hr}$ ). Inside the $220 \mathrm{~K}$ isotherm, heavier rainfall was observed at Lai-i/41.5 and Nanjou/ $32.5 \mathrm{~mm} / \mathrm{hr}$. The rainfall on both sides of the Hengchun Peninsula was very heavy; however, that on the wind slope was somehow stronger than that on the lee side. Note that no rain was reported in the previous one-hour period on this peninsula (see Table 5). From the analysis of GMS IR images, the mechanism that caused heavy rainfall at that time, was not certain. Perhaps other systems occurred and then merged with MCS\#1 in such a short time that they could not be seen in the hourly GMS images. According to the 20:32Z GMS image, a cold cloud was found to the west of MCS\#1, which may be a sign that a new system is about to occur. It grew and moved into southern Taiwan at 22:25Z, and then merged with MCS\#1, thus enhancing the strength of the original MCS. This is the most likely reason for the heavy rainfall events that occurred at 22:25Z.

At 23:32Z, the GMS satellite observed southern Taiwan and the TRMM satellite also passed this area at 23:29Z. The retrieved oceanic rainfall distributions are shown in Fig. $7 \mathrm{~g}$. The $240 \mathrm{~K}$ isotherm still included rainfall regions, and the $210 \mathrm{~K}$ isotherm had almost moved back over the ocean again. However, within the $210 \mathrm{~K}$ isotherm, an $\mathrm{RR}$ of $34 \mathrm{~mm} / \mathrm{hr}$ was still observed at the junction of plain and peninsula. Meanwhile, the TMI Tbs retrieved a rainfall maximum of $8.9 \mathrm{~mm} / \mathrm{hr}$ over the ocean, showing that the threat of heavy rainfall still existed.

The rain stations shown in Table 5 are arranged from south to north. The light dashed area stands for no rain and the dark dashed area for rainfall greater than $30 \mathrm{~mm} / \mathrm{hr}$. Rainfalls larger than $30 \mathrm{~mm} / \mathrm{hr}$ had a tendency to move southward from $16 \mathrm{Z}$ to $24 \mathrm{Z}$. The temporal and spatial variabilities of rainfall over this region were extremely large. An MCS from the ocean with an RR of $6 \mathrm{~mm} / \mathrm{hr}$ could cause heavy rainfall over land on Taiwan with RRs of up to about $80 \mathrm{~mm} /$ $\mathrm{hr}$. However, racing the IR Tb isotherms should reveal some temporal and spatial information on heavy rainfall. If the investigation of rainfall amounts over the water and the land affected by the same MCS have been reached, the performance of heavy rainfall forecasting would be improved significantly by remote sensing techniques combining IR and MW data.

\section{CONCLUSIONS}

Using GMS IR isotherms to define the life stages of an MCS and the rainfall commencement threshold, for the purposes of predicting rainfall intensity and amounts, could lead to unavoidable errors. In addition, using IR techniques to estimate rainfall measurements is an indirect method that could be misled by cirrus clouds, for example. On the other hand, the MW remote sensing technique is a better way to estimate the RR over the ocean. Furthermore, combining IR and MW remote sensing techniques would improve the prediction performance for heavy rainfall caused by MCSs or other weather systems.

In this paper, the TMI nine-channel Tbs-RR equation is used to retrieve oceanic RR distributions during SCSMEX. From the analysis of RR distributions in relation to GMS IR Tb contours, the rainfall region was found to be concentrated in the forward portion of the MCS in the direction of movement. The IR Tb $240 \mathrm{~K}$ isotherm can include such rainfall regions. Heavy rainfall occurred in regions enclosed by the $220 \mathrm{~K}$ isotherms and the rainfall maximum always occurred inside the $210 \mathrm{~K}$ isotherm. In the case of a dissipating MCS, the rainfall maximum 
was retrieved outside the $210 \mathrm{~K}$ isotherm but within the region between the $210 \mathrm{~K}$ and $220 \mathrm{~K}$ isotherms. Moreover, the rainfall distribution on land was affected by the evolution of $210 \mathrm{~K}$ and $220 \mathrm{~K}$ isotherms. However, over land, the $240 \mathrm{~K}$ isotherm also could include rainfall regions.

The heavy rainfall observed by the coastal rain stations reveals that the curved coastline might have contributed to local rainfall enhancement. The unique curved shape of a coastline also affects an MCS during its landfall. The effect of topographic flow blocking on the formation and maintenance of a mesolow could explain the heavy rainfall that happens in cases where the strength of an MCS was not great enough to climb over the CMR. As an example of local rainfall enhancement, an MCS from the ocean with an RR of $6 \mathrm{~mm} / \mathrm{hr}$ can cause rainfall with an RR of up to $80 \mathrm{~mm} / \mathrm{hr}$ over the land. Moreover, once an MCS affects southern Taiwan, the Hengchun Peninsula has heavy rainfall. This might be due to the orographic features of this peninsula are not so steep and the mountain ridges are mostly lower than $500 \mathrm{~m}$. Local orographic rainfall enhancement is apparent on this peninsula. Once quantitative oceanic RRs are known, the orographic effect on the local rainfall can be measured.

As for rainfall events that cannot be definitely explained, a partial reason could be the poor temporal resolution of observations from space. At present, the observation time interval is at least one hour for GMS and one day for TRMM. Even though this temporal resolution of such satellite observations is not enough to analyze some mesoscale convective weather systems, there is a lack of radio sounding stations on the open ocean, so the meteorological satellite is the only available observatory. Except for the temporal resolution, a combination of MW and IR remote sensing algorithms to probe oceanic rainfall is a very promising technique, at this time. In the future, we are looking forward to including rain data from buoys (which was not available for this paper), and higher spatial resolution and more coincidental data from PR and VIRS on the TRMM satellite. This addition could reduce the beam-filling bias of RR rerievals. Moreover, by adding more than one year's observations to this algorithm, the extension and performance in future study can be measured.

Acknowledgements The authors gratefully acknowledge the helpful comments and suggestions of Professor Ging-Rong Liu of Central University and two anonymous reviewers. The data used in this paper were acquired as part of the TRMM. The algorithms were developed by the TRMM Science Team. The data were processed by the TRMM Science Data and Information System (TSDIS) and the TRMM office; they are archived and distributed by the Goddard Distributed Archive Center. TRMM is an international project jointly sponsored by the Japan National Space Development Agency (NASDA) and the US National Aeronautics and Space Administration (NASA) Office of Earth Science. We would like to thank the Central Weather Bureau on Taiwan for providing valuable rain data from the SCSMEX. Special thanks go to Drs. C. Kummerow and E. J. Nelkin for their help with the TRMM data and for providing a radiative transfer model.

\section{REFERENCES}

Akaeda, K., J. Reisner, and D. Parsons, 1995: The role of mesoscale and topo-graphically induced circulations in initiating a flash observed during the TAMEX project. Mon. 
Wea. Rev., 123,1720-1739.

Arkin, P. A., 1979: The relationship between fractional coverage of high cloud and rainfall accumulations during GATE over the B-array. Mon. Wea. Rev., 107, 1382-1387

Arkin, P. A., and B. Meisner, 1987: The relationship between largescale convective rainfall and cold cloud over the Western Hemisphere during 1982 - 1984. Mon. Wea. Rev., 115, 51-74.

Chen, T. J. and C. C. Yu, 1990: Role of Mei-Yu front and mesolow on the heavy rainfall events: two cases in TAMEX phase 1. Atmos. Sci. (in Chinese), 18, 129-147.

Chi, S. S. and T. J. Chen, 1988: A diagnostic case study of the environmental conditions associated with mesoscale convective complexes: 27-28 May 1981 case. Atmos. Sci. (in Chinese), 16, 14-30.

Chiu, T. K., S. T. Wang, Y. W. Lin, and C.-S. Chen, 1986: A study of the movement of mesoscale convective system from southern China to Taiwan area. Atmos. Sci. (in Chinese), 13, 121-132.

Chiu, L. S., G. R. North, D. A. Short, and A. McConnell, 1990: Rain estimation from satellites. : Effect of finite field of view. J. Geophys. Res., 95, 322-327

Holinger J., R. Lo, G. Poe, R. Savage, and J. Pierce, 1987: Special Sensor Microwave/ Imager user's guide, NRL Tech. Rep., Naval Research Laboratory, 120 PP.

Hong, Y., C. D. Kummerow, and W. S. Olson, 1999: Separation of convective and stratiform precipitation using microwave brightness temperature. J. Atmo. Ocean. Tech., 38, 1195 1213.

Kummerow, C., R. A. Mack, and I. M. Hakkarinen, 1989: A self-consistency approach to improve microwave rainfall rate estimation from space. J. Appl. Meteor., 28, 869-884.

Kummerow, C., and L. Giglio, 1995: A method combining passive microwave and infrared rainfall observations. J. Atmo. Ocean. Tech., 12, 33-45.

Kummerow, C., W. Barnes, T. Kozu, J. Shiue, and J. Simpson, 1998: The tropical rainfall measuring mission (TRMM) sensor package. J. Atmo. Ocean. Tech., 15, 809-817

Lin, Y. L., 1993: Orographic effects on airflow and mesoscale weather systems over Taiwan. $T A O, 4,381-420$

Maddox, R. A., 1980: Mesoscale convective complex. Bul. Amer. Meteor. Soc., 61, 13741387

Masahito, W. and M. Shinoda, 1995: Long-term variability of Asian monsoon rainfall during 1946-1988. J. Meteor. Soci. Japan, 74, 923-934.

Simpson, J., C. Kummerow, W. K. Tao, and R. F. Adler, 1996: On the tropical rainfall measuring mission (TRMM). Meteor. Atmo. Phys., 60, 19-36.

Spenser, R. W., 1986: A satellite passive 37-GHz scattering-based method for measuring oceanic rain rates. J. Clim. Apl. Meteor., 25, 754-766

Wilheit, T. T., and A. T. C. Chang, 1980a: Atmospheric corrections to passive microwave observations of the ocean. Boundary Layer Meteor., 18, 65-77

Wilheit, T. T., and A. T. C. Chang, 1980b: An algorithm for retrieval of ocean surface and atmospheric parameters from the observations of the scanning multichannel microwave radiometer. Radio Sci., 15, 525-544. 